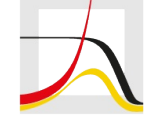

MAX PLANCK INSTITUTE

FOR DEMOGRAPHIC RESEARCH

Konrad-Zuse-Strasse 1 · D-18057 Rostock · Germany · Tel +49 (0) 3812081 - 0 · Fax +49 (0) 3812081 - $202 \cdot$ www.demogr.mpg.de

MPIDR Working Paper WP 2022-008 I February 2022

https://doi.org/10.4054/MPIDR-WP-2022-008

\title{
Countries Embracing Maternal Employment Opened Schools Sooner after Covid-19 Lockdowns
}

Natalie Nitsche I nitsche@demogr.mpg.de Ansgar Hudde I hudde@wiso.uni-koeln.de 


\title{
Countries Embracing Maternal Employment Opened Schools Sooner after Covid-19 Lockdowns
}

\author{
Natalie Nitsche ${ }^{1}$, Ansgar Hudde ${ }^{2}$ \\ ${ }^{1}$ Max Planck Institute for Demographic Research. \\ ${ }^{2}$ University of Cologne \\ * Corresponding authors: Natalie Nitsche, Ansgar Hudde \\ Email: nitsche@demogr.mpg.de, hudde@wiso.uni-koeln.de
}

\section{Keywords}

COVID-19, containment measures, gender ideology, school closures, gender ideology bias

Acknowledgements: We thank Maarten Bijlsma, Mikko Myrskylä and the participants of the MPIDR lab talk for helpful comments and suggestions. 


\begin{abstract}
The Covid-19-pandemic-related closure of schools has affected the majority of the world's students and remains a contentious issue. Using data from the UNESCO school database, the ISSP 2012, and country-level panel regressions, we leverage simultaneous school closures during the first wave of Covid-19 lockdowns to estimate the effect of gender ideology on school reopening schedules. We show that societal gender ideology has likely influenced school reopening policies: i.e., that societies with more supportive attitudes toward maternal employment reopened schools significantly sooner, and at higher intensities, than societies with less supportive attitudes toward maternal employment, relative to other reopening measures, and net of infection rates. Our findings suggest a causal effect of gender ideological beliefs regarding pandemic-related school closure policies. We test and exclude a variety of potential confounders, such as a country's maternal employment rate, GDP, social spending, and cultural values toward children. We argue that school closures may be perceived as less problematic in countries where more people support the ideal of a stay-at-home mother. Gender attitudes may thus represent a set of ideas that affect policy-makers' decision-making via gender ideology normative framing or a potential gender ideology bias. However, the specific underlying mechanisms through which the gender ideology effect operates at the policy-maker level remain untested in our study, and should be investigated by future research.
\end{abstract}

\title{
Introduction
}

Since the beginning of the Covid-19 pandemic, a wide array of virus transmission control measures have been implemented. Among them have been school closures of unprecedented scope. In April 2020, during the first phase of the Covid-19 pandemic, almost $90 \%$ of the world's enrolled students were affected. Between February 2020 and November 2021, schools were shuttered for 50 weeks or more in $32 \%$ of the world's 
countries $^{1}$ (UNESCO 2022). In January 2022, during the Omicron wave, schools are still, or again, shuttered in various countries (Burbio 2022; UNESCO 2022).

Pandemic control measures have unintended and often detrimental side effects (Kampf and Kulldorff 2021; Polyakova et al. 2020). These side effects are particularly severe in the case of school closures, because they seem to lead to a variety of adverse consequences, including massive and often socially stratified learning losses (Donnelly and Patrinos 2021; Engzell, Frey, and Verhagen 2021; Jæger and Blaabæk 2020; Sabates, Carter, and Stern 2021); deteriorating mental health among children and parents (Calarco et al. 2020; Golberstein, Wen, and Miller 2020; Russell et al. 2020; R. Viner et al. 2021; Zamarro and Prados 2021); increases in child maltreatment (Humphreys, Myint, and Zeanah 2020); and worsening of health-related behaviors among children, such as declines in physical exercise and increases in screen time (Alonso-Martínez et al. 2021; Schmidt et al. 2020; R. Viner et al. 2021; Burkart et al. 2022).

School closures also generate a disproportionally large burden for parents, in particular for mothers. Alongside mothers, fathers have been spending more time on childcare during the pandemic, which has, in turn, increased their share of the average number of hours couples spend on childcare in some contexts (Andrew et al. 2020; Carlson, Petts, and Pepin 2021; Chung et al. 2021; Del Boca et al. 2020; Hank and Steinbach 2021; Kreyenfeld and Zinn 2021; Yerkes et al. 2020). However, several studies have found that mothers have largely compensated for the additional domestic work caused by school closures, and that, in absolute hours, they have increased their childcare hours more than fathers have (Boca et

\footnotetext{
${ }^{1}$ Own calculation using the dataset "Total duration of school closures" (UNESCO 2022).
} 
al. 2021; Del Boca et al. 2020; Meraviglia and Dudka 2021; Yildirim and Eslen-Ziya 2021; Farre et al. 2020; Sevilla and Smith 2020; Xue and McMunn 2021). Furthermore, compared to fathers, mothers have shouldered more of the additional "emotional work" in families, have been more affected by job losses and reductions in employment hours, and have been more likely to experience mental health declines and perceived work-life conflicts (Collins et al. 2021; Del Boca et al. 2020; Dias, Chance, and Buchanan 2020; Landivar et al. 2021; Ma, Sun, and Xue 2020; Qian and Fuller 2020; Hjálmsdóttir and Bjarnadóttir 2021; Hiekel and Kühn 2021; Ruppanner, Tan, et al. 2021; Yamamura and Tsustsui 2021; Zamarro and Prados 2021; Frank et al. 2021; Yerkes et al. 2020). Thus, as well as harming children, school closures have been associated with significant increases in gender inequalities in the domestic sphere, the labor market, and mental health. Examining the factors that affected the duration and the intensity of school closures, net of Covid-19 infection rates, is therefore of great importance.

While school closures were an almost universal occurrence at the beginning of the first set of lockdowns in March 2020, the pace of school reopenings in the subsequent months of 2020, relative to other societal reopenings, varied widely. Similarly, further Covid-19 waves throughout 2020, 2021, and early 2022 have triggered school closures in some, but not in other countries and regions. Thus, there has been broad variation in types and the usage of pandemic response measures across societies, in particular regarding schools (Blum and Dobrotić 2020; Landivar et al. 2021; McGowan 2020). Two years into the Covid-19 pandemic, the scientific evidence on the role of schools in and the effects of school closures on the spread of SARS-CoV-2 remains mixed and inconclusive (Stage et 
al. 2021; Walsh et al. 2021; Wu et al. 2022). Given this lack of clear epidemiological guidance on best Covid-19 pandemic practices for schools, other factors, such as economic, political, or ideational considerations, have likely influenced how political actors have managed school operations during the pandemic, leading to the observed heterogeneous pandemic policies related to schools, and other public and private institutions (Béland et al. 2021). However, to date, the question of whether and, if so, which ideational aspects explain these differences in the changes to school operations in response to the Covid-19 pandemic has yet to be fully answered.

Our study addresses this question. We hypothesize that gender role ideological beliefs represent an important ideational component that affected school operation policies during the pandemic. School closures mean that children need to be educated and cared for at home, which adds to parents' care and domestic workloads. When the pandemic began in late 2019, it was well-documented that women were carrying out the majority of domestic and care work in families around the globe (Bianchi et al. 2012; Van der Lippe et al. 2011; Treas and Tai 2016; OECD 2018). Therefore, in March and April 2020, the potential implications of the pandemic control measures in terms of growing gender inequalities in the private and the public sphere were widely discussed in the media (UNESCO 2021b). It may be assumed that decision-makers were aware that mothers would likely bear the main responsibility for compensating for school closures. Thus, we hypothesize that decisionmakers' gender attitudes represent a set of ideas that may have affected their school-related pandemic responses, as these attitudes - perhaps unwittingly - were shaping their costbenefit assessments of closing schools relative to closing other parts of public life, such as culture, sports, or commerce. 
Specifically, we investigate whether societal attitudes toward maternal employment have contributed to country-level variation in the pace and intensity of school reopenings following the school closures triggered by the first Covid-19 outbreak in early 2020 . We follow school operations until August 1,2020. We borrow from the literature that theorizes the role of ideas in policy-making. We lean on the concepts of "ideas as institutional frameworks" and "ideas as heuristics" in influencing policy-making (Swinkels 2020), and theorize that the effects of gender role attitudes toward maternal employment operated at both the individual cognitive level and the normative institutional level, albeit in the background. We argue that gender attitudes may have made their way into problem definitions and policy formulations via policy-makers' complex conscious and subconscious perceptions regarding the costs and benefits of school closures, and via the formation of a normative guiding principle in uncertain times. We call this normative framing and potential cognitive bias in policy decision-making gender ideology normative framing or gender ideology bias.

Our study leverages the exogenous shock of the first Covid-19 pandemic phase, which led to an almost simultaneous closing of schools in most nations across the globe, to estimate the effect of societal-level gender ideologies on countries' school reopening schedules. We trace school opening status until August 1,2020, which marks the point when the first pandemic phase had ended, and the academic summer break had started in most of the Northern Hemisphere. We find that countries with more supportive attitudes toward maternal employment reopened schools sooner and at greater intensities, relative to other societal reopenings. These findings suggest that each country's specific mix of policies aimed at curbing the spread of SARS-CoV-2 was partly guided by the society's attitudes 
toward maternal employment. While we cannot test the specific individual- and discursivelevel mechanisms through which gender ideology affects policy-making, we test and exclude a variety of potential confounders, such as a country's maternal employment rate, GDP, social spending, and cultural values toward children. Our findings thus indicate that ideas regarding maternal employment indeed affected the duration and intensities of school closures after the first COvid-19 lockdowns via a potential gender ideology bias.

\section{Background}

\section{The role of ideas in policy-making}

Scholars who study policy-making are increasingly emphasizing the importance of ideas e.g., norms, beliefs, world views, ideologies, attitudes, and cognitive heuristics and biases - for policy decision-making (Jacobsen 1995; Schafer and Walker 2006; Campbell 2002; Esping-Andersen 1999; Cairney 2019; Béland and Cox 2010). Theorizing on the role of ideas in policy-making gained momentum in the early 1990s (Goldstein and Keohane, 1993; Jacobsen), and is experiencing a renewed upsurge in the current "ideational turn" in policy scholarship (Swinkels 2020). However, conceptualizing and measuring ideas, and tracing their precise pathways of influence on policy-making, have proven challenging (for overviews, see Béland 2016; Campbell 2002; Cairney 2019; Campbell 2008).

Ideas, social policies, and social outcomes are likely connected in complex ways. They may, for example, relate to each other through feedback loops or complex interactive processes (Budig, Misra, and Boeckmann 2012; Gangl and Ziefle 2015; Padamsee 2009). 
Determining the levels at which they operate (e.g., at the individual policy-maker, institutional, or discursive level) and their precise mechanisms of influence has often proven difficult (Campbell 2002; Gangl and Ziefle 2015; Padamsee 2009; Sjöberg 2004; Tjernström and Tietenberg 2008; John 1999). Efforts to tackle these challenges have been accompanied by debates on the appropriate methods for doing so, including whether and, if so, how the causal "effects" of ideas on policy-making can be isolated and identified (Yee 1996; Béland 2016; Swinkels 2020).

Despite these difficulties, the role of ideas in policy-making has evolved into a central concept for understanding and explaining policy-making processes and policy changes (Béland and Cox 2010; Campbell 2008; Béland 2009; 2016; Cairney 2019). This scholarship has emphasized the need to define and measure ideas precisely; to clearly articulate the mechanisms through which ideas are hypothesized to "affect" policymaking; and to choose appropriate methodologies for empirical analyses. Therefore, in the following, we argue that when analyzing the potential influence of gender ideology on policy-making, it is essential to theoretically differentiate between i) the what, i.e., the specific content of the idea; ii) the who, i.e., the actors and the societal levels on which they operate; and iii) the how, i.e., the processes and mechanisms through which ideas enter the policy-making process. In addition to defining the what, the who, and the how of the influence of gender ideology on policy-making, we carefully consider and choose an empirical measure of gender attitudes and an appropriate analytical strategy to address our research question. 


\section{Conceptualizing gender role ideology as a predictor of policy-making: The what}

Regarding the what of ideas, several scholars have argued that "conceptual confusion" (Campbell 2008, 164) exists in the ideational literature on policy-making (Cairney 2019; John 2003). While the literature has offered a wide array of definitions of ideas - from "attitudes" to beliefs and norms to values (Campbell 2002) - Cairney $(2019,224)$ pointed out that a critical condition for an "idea" to affect the policy-making process is that it is shared by others. He further argued that these shared beliefs can be both "visible or widely taken for granted." This perspective is related to Campbell's typology of ideas, which classifies ideas as being either cognitive or normative, and as acting either in the "foreground" or the "background" of political processes (2008, 166). Béland (2016) extended this typology by arguing that as ideas can appear in many forms, "instead of simply defining ideas in abstract terms, we should look at their potential impact across the policy cycle" (738). This represents a compelling argument for analytically separating the "what" of an idea from the procedural "how" of its impact on policy-making. We further suggest that the "what" of an idea also needs to be specific; in other words, it should be tied to or specified in reference to a certain social issue, group, or both to ensure that it is clearly definable, measurable, and suitable for inclusion in empirical policy analyses.

In terms of the ideational what, our study focuses on the specific idea of gender role attitudes toward maternal employment. We argue that attitudes toward maternal employment are shared, normative, and "taken for granted" beliefs that affected schoolrelated policy-making in the first pandemic phase, mostly while acting in the background. In terms of the ideational who and how, the next section argues that attitudes toward 
maternal employment mattered in the form of cognitive heuristics and normative institutional frameworks, which likely acted on the individual level, and guided problem definitions and policy formulations in school-related policy-making processes in the phase following the first SARS-CoV-2 outbreaks in the spring and summer months of 2020.

There is a long tradition in the social sciences of theorizing about societal gender roles in terms of expectations, attitudes, norms, values, or, more generally, gender role ideology; and measuring this concept empirically (Davis and Greenstein 2009; Mason and Bumpass 1975). Gender role ideologies incorporate a variety of shared cultural beliefs about both the gendered traits and the social responsibilities of men and women in the family, the labor market, and beyond (Charles and Grusky 2005; Kroska 2007; Ridgeway and Correll 2004).

Generally speaking, gender essentialist beliefs, also called "traditionalism," support the idea of "separate gender spheres," in which women's responsibilities are seen as centered on the family and private realm, and men's responsibilities are seen as centered on the labor market. This traditionalism stands in opposition to "gender egalitarianism" or the idea of “joint spheres," in which women and men are seen as equally adapted to and responsible for performing tasks in the family or private realm on the one hand, and the labor market or public domain on the other (Davis and Greenstein 2004; 2009).

Previous scholarship has demonstrated that the gender ideological thinking of individuals is complex and goes beyond a simple dichotomization of "egalitarian versus essentialist" ideologies (Knight and Brinton 2017; Scarborough, Sin, and Risman 2019; Hudde 2018). Instead, a variety of gender ideological constructs with mixed elements of egalitarian and essentialist ideas seem to co-exist in, for instance, the ideals of "intensive parenting" or 
“egalitarianism with essentialist elements" (Grunow, Begall, and Buchler 2018), as was suggested early on in the multi-factorial approach to gender ideology (Spence 1993). Thus, it is necessary to conceptualize and measure gender ideology specifically in reference to certain spheres of life, such as gendered ideals of childrearing or beliefs about the labor market involvement of mothers. Moreover, this scholarship has underscored the relevance of formulating specific, measurable ideas for analyzing ideational influences on policymaking in the realm of gender ideology and beyond. Maternal employment is among the social outcomes most heavily affected by Covid-19 school closures (Carson, Ruppanner, and Ratcliff 2020; Collins et al. 2021; Heggeness 2020; Landivar et al. 2021; Del Boca et al. 2020). We have therefore chosen attitudes regarding maternal employment as the relevant measure of gender ideology for our study, and hypothesize that attitudes toward maternal employment likely played a central role in social policy decision-making regarding pandemic-related school measures.

\section{Conceptualizing gender role ideology as a predictor of policy-making: The who and}

\section{the how}

There is a long tradition of feminist scholarship that theorizes about how gender and ideas about gendered societal roles, particularly regarding mothers, motherhood, and caring, are interwoven with social policies and welfare state regimes (Adams and Padamsee 2001; Fraser and Gordon 1994; Kremer 2007; Orloff 2018; Padamsee 2009; Pfau-Effinger 2005a; Pfau-Effinger 1998). However, this largely theoretical literature on the gender-social policy nexus has remained somewhat disconnected from the core debate about ideas and 
policy-making (Béland 2009). Nonetheless, in parallel to scholarship on the role of ideas in policy-making, this feminist literature has provided insight into how "deeply embedded cultural assumptions influence the design and selection of concrete policy alternatives" (Béland 2009, 568); and has emphasized the relationship between ideational processes, categorical inequalities, and power relations in policy-making and welfare regimes.

Feminist perspectives on how ideas about gendered social roles shape policy-making

Feminist scholars have argued that ideas about gendered roles and power relations assign different degrees of value and worth to certain types of activities, while simultaneously characterizing them as male or female, which implies, among other things, the devaluation of care work, which is largely carried out by women (England 2005; Fraser and Gordon 1994; Pfau-Effinger 1998; Reskin 1988). This reasoning is backed up by the findings of recent empirical research in the field of psychology, which demonstrate that care work is indeed perceived as being of lower worth than STEM careers (Block, Croft, and Schmader 2018).

In other words, feminist theorizing about the influence of ideas on gender and gendered social roles has argued that these ideas inherently imply the assignment of value; create realms of "social inclusion" versus "social exclusion" (Pfau-Effinger 2005b); and, ultimately, assign power to the dominant groups in welfare states and policy-making. This perspective is in line with Cairney's assessment that "the attempt to marry the concepts of power and ideas...is a key feature of the literature on ideas" $(2019,224)$. He suggested that the strength of employing ideas in policy-making analysis lies in "identifying how power and ideas combine to produce a more convincing explanation of policy processes and 
outcomes" (ibid.).

Starting in March 2020, pandemic containment measures shut down economic, social, and educational institutions and activities in countries around the world. Soon thereafter, intense debates about the reopening of these institutions ensued (Hale et al. 2020). Leaning on the reasoning that power and ideas combine in influencing policy-making, it can be argued that ideas played a role in reopening plans. More rapid reopenings can be equated to assigning greater privilege and power to the affected social groups. Longer and more comprehensive school closures thus imply that the society assigns less power to mothers. It can therefore be expected that the more highly a society values maternal employment, the sooner and the more comprehensively it reopened schools relative to other societal reopenings. Thus, it can be argued that the pace of school reopenings corresponded to the value the society places on mothers' labor market contributions, and to the society's perceptions of the economic and social gains mothers can derive from them.

\section{Horizontal and vertical axes of how ideas enter policy-making processes}

Swinkels (2020) and Béland (2009) offered important conceptual frameworks that further guide our theorizing regarding how ideas about maternal employment have entered the policy-making process. Swinkels (2020) reflected on the social level at which ideas operate in policy-making. She classified ideas as explanatory forces for policy-making along three central analytical lines: ideas as heuristics, ideas as strategic tools, and ideas as institutional frameworks. The concepts of ideas as heuristics and ideas as institutional frameworks are of particular relevance to our reasoning. Ideas as heuristics, cognitive biases, or "cognitive short-cuts" originate from "microfoundations" - i.e., policy-makers' cognition (Swinkels 
2020, 288), or their "taken-for-granted worldviews" (Campbell 2002, 22) - and operate at the level of the individual actors. Such beliefs are subjective, and thus provide a "colored lens" through which reality is perceived, and which constrains policy-makers' choices when considering policy alternatives (Swinkels 202, p. 284). Particularly in situations in which people face acute time pressure, limited information, and complex circumstances or choices, their decisions can be guided by and based on cognitive heuristics, biases, and information unrelated to the issue at hand (Tversky and Kahneman 1974; Songer and Lindquist 1996; Stepanikova 2012; Lau and Redlawsk 2001). Ideas as cognitive heuristics work "from the inside out."

By contrast, ideas as institutional frameworks work "from the outside in," as Swinkels has argued. Institutional frameworks operate at the normative societal level and "can be understood as intersubjective understandings embedded in institutions and societies" (Swinkels 2020, 286). They serve as guiding principles whose function as a decisionmaking aide is heightened in times of uncertainty and crisis (Blyth 2001). The importance of institutional frames or normative guiding principles is twofold: first, they can serve as shared beliefs among policy-makers, potentially enabling them to reach consensus faster when under pressure; and, second, they represent a normative climate, or a reflection of the prevailing social values, which policy-makers can cater to in their decision-making in an attempt to secure both social acceptance and re-election (Pfau-Effinger 2005b, 10).

While Swinkels' classification sorted ideas into a top-down schema, Béland (2009) dissected the policy-making process horizontally, into three phases: the first phase consists of defining the problem; the second phase involves formulating policies and policy 
alternatives; and the third phase involves the use of discursive frames by actors to challenge or confirm existing policies (568). The lenses of problem definition and policy formulation, combined with Swinkels' horizontal typology of ideas as cognitive heuristics and institutional frames, are particularly useful for developing our hypotheses on the role of gender role attitudes in prioritizing school reopenings during the pandemic.

\section{How have attitudes about maternal employment affected school reopenings? Hypotheses}

During the first Covid-19 pandemic phase, expert task forces and executive bodies dominated governmental decision-making on containment measures and policies, while the levels of influence of public discourse and national parliaments were rather low (Rajan et al. 2020; Griglio 2020). In addition, firm scientific information on the transmission of SARS-CoV-2 in school settings was scant in the first half of 2020. This set of circumstances implies that the conditions were favorable for both ideas as heuristics and ideas as institutional frameworks to carry significant weight in the policy decision-making process during the first wave of Covid-19 lockdowns and the subsequent reopening phase. We argue that attitudes regarding maternal employment had a significant impact both at the individual level via cognitive heuristics, and within the discursive decision-making process among policy-makers via institutional frameworks.

In terms of cognitive heuristics, we suggest that the more individual policy-makers embraced gender essentialist values, which include the ideal of a stay-at-home mother, the lower they perceived the immediate costs of leaving schools closed to be, relative to the 
costs of keeping other institutions, such as workplaces, stores, or leisure activities, closed. In other words, the lower policy-makers valued maternal employment in the labor market, the more they may have assumed that mothers and children are well-served when caretaking occurs in the home, rather than in schools; and the less valuable and the less urgent they may have perceived the ability of mothers to send their children to school and to redirect their attention to labor market employment. This cognitive heuristic based on ideas about gendered social roles likely also affected their decision-making about the intensity at which school reopenings occurred, e.g., whether students returned to school staggered by grades or all at once, and whether all students returned simultaneously or in smaller group sizes based on makeshift schedules. We call this cognitive gender attitudinal bias, which may have affected the perception of shuttered schools as problematic, and subsequently affected the formulation of school reopening policies, gender ideology bias.

In terms of institutional frames, we suggest that even when policy-makers did not have gender ideology bias at the individual level, societal attitudes toward maternal employment served as an important guiding principle for their decisions about which institutions should be prioritized in the reopening process following the first lockdowns of 2020. Policymakers may have used their conscious or unconscious assessments of societally shared attitudes toward the role of mothers in society to gauge to what degree shuttered schools were perceived as problematic, how the public would tolerate long school closures, and what policy formulations for reopening schools would be considered acceptable by the groups of policy-makers who were in charge at that time.

Schools were closed in most countries in March 2020 in an attempt to curb the transmission 
of SARS-CoV-2, regardless of the prevailing gender ideology in each society. Leaning on Beland (2009), we hypothesize that ideas about maternal employment affected the reopening process in two phases. First, these ideas affected whether closed schools were perceived as a problem in need of alleviation, relative to other societal closings. This perception should have influenced the length of time until the first school reopenings, relative to other openings. Our first hypothesis is therefore as follows:

H1: Ideas about gender roles, operating as cognitive heuristics and institutional frameworks, affected whether shuttered schools were perceived as a problem in need of alleviation, relative to other societal closings. These ideas, therefore, affected the length of time until the schools reopened. The greater the attitudinal support for maternal employment, the faster the schools were reopened.

Second, we hypothesize that once school closures were perceived as problematic and reopenings were targeted, attitudes about maternal employment affected the precise subsequent school reopening policy formulations, and were mirrored in the intensity at which schools allowed students to return. Countries used various reopening strategies, ranging from full to partial reopening, either staggered by grades or based on limited group sizes, or contingent on the spread of the virus in the community. Our second hypothesis is therefore as follows:

H2: Ideas about gender roles, operating as cognitive heuristics and institutional frameworks, affected the details of school reopening policy approaches. The higher the 
attitudinal support for maternal employment, the more comprehensively schools were reopened.

\section{Method and data}

\section{Analytic strategy and potential confounders}

To analyze how attitudes toward maternal employment have affected school reopening schedules, we leverage the shock of the first set of Covid-19 waves and the ensuing school closures. The pandemic shock hit all countries unexpectedly, regardless of their gender ideology (Engel 2016) and the majority of countries around the globe reacted to the pandemic by closing their schools in spring 2020. Of the countries in our sample, schools were shuttered in all but four. As school attendance is compulsory in all countries (UNESCO Institute for Statistics 2020), countries faced equal levels of pressure to reopen schools from an educational-legal perspective. This identification strategy ensures that all countries had the same reopening conditions; in other words, their expected outcomes in terms of the timing and intensity of school reopenings were the same, i.e., they were exchangeable (Hernán and Robins 2020). Hence, we assume that the differences in the timing and the intensity of school reopenings - relative to other societal reopenings - were rooted in deliberate prioritization.

We use descriptive statistics and country-level panel regression models to estimate the causal effects of gender ideology, measured as attitudes toward maternal employment, on the timing and the intensity of school reopenings. Specifically, we estimate the daily 
status of school reopenings in each country after its day of maximum lockdown. We conceptualize the day of maximum lockdown as the day when the maximum amount of time was spent in residential areas, as measured by Google's COVID-19 Community Mobility Reports for each country (Google LLC 2020). The average maximum amounts of time spent in residential areas, and the subsequent declines therein, do not differ between countries depending on their degree of support for maternal employment (see Figure 1).

We argue that the effects of attitudes toward maternal employment on H1) the timing and H2) the intensity of school reopenings can take two pathways. First, policymakers might be guided by their own attitudes about maternal employment, and could be affected by gender ideology bias. Second, policy-makers might be guided by widespread attitudes in the population, which might serve as their norms or institutional frameworks. Ideally, to test and distinguish between these two pathways, we would analyze attitudinal data on the individual policy-makers (first pathway) and on the general public (second pathway). Unfortunately, data on the pre-pandemic gender ideologies of policy-makers involved in school reopening decisions are not available. However, representative survey data on attitudes about maternal employment in the general population are available for many countries, and we use these data in our analyses.

We cannot simply infer from the average attitudes in the population what the attitudes of the decision-makers were regarding school reopenings. However, it seems plausible that policy-makers in a country where the people are highly supportive of female employment should, on average, be more supportive of female employment than policymakers in a country where the people are not supportive of female employment. In other 
words, we assume that average attitudes in the population correlate with those of the relevant actors in political power, who gave recommendations for and made decisions about school reopening schedules during and after the first wave of Covid-19 lockdowns. If we identify an effect of a country's average gender ideology on the country's school reopening decisions, this suggests that either one or even both of the theoretically developed pathways are at work; but we cannot clearly distinguish between the two.

The assumption on which our strategy to identify the effect of gender ideology rests is that no other factors that are correlated with gender ideology, but that are omitted from the analysis, drive the effect (omitted-variable bias). A variety of other factors may have altered school reopening incentives and affected reopening schedules, such as differences between countries in their actual maternal employment rates, levels of economic strength, population age structures, and diffusion of the internet and digital home schooling. Hence, the central assumption on which our identification strategy of the effect of gender ideology rests is that no other factors that are correlated with gender ideology, but that are omitted from the analysis, drive the effect. We have conducted an extensive set of robustness checks to test this assumption (described below).

Gender ideology was measured before the pandemic started. This ideology often reflects deeply ingrained beliefs, which tend to change only slowly and incrementally within societies (Sullivan, Gershuny, and Robinson 2018; Knight and Brinton 2017). Hence, our estimate of the influence of gender ideology on school reopening schedules is not contaminated by self-selection into ideology contingent on the outcome.

As was argued, decision-making is particularly affected by biases and normative 
institutional frameworks when policy-makers are under acute time pressure, uncertainty, and limited information. We therefore limit our analyses to the very first set of school closings in March 2020 and the subsequent months until the end of the first Covid-19 pandemic phase. Thus, we analyze the time frame between each country's maximum lockdown day (April 3, on average) and the beginning of the summer break or any other academic break that was at least four weeks long, or August 1, if no such break occurred before then.

Our approach has limitations. They lie in the lack of individual-level data from policy-makers to test the suggested causal mechanism rooted in individuals' cognitive gender ideology bias, and the observational nature of the data; i.e., countries are not randomly assigned a certain level of attitudinal support for maternal employment. Thus, despite the extensive set of robustness checks we conducted, we cannot exclude the existence of unmeasured confounders. The limitations and the threats to the causal inference of this study are discussed in greater detail in the discussion section.

\section{Measures}

Attitudes toward maternal employment. The data on attitudes toward maternal employment come from the Changing Gender Roles IV-module of the 2012 International Social Programme (ISSP) 2012 (ISSP Research Group 2016). This dataset is best suited for our research purposes because it contains several relevant items, covers a large number of countries, and allows us to create a measure of attitudes toward maternal employment that are representative of the whole population in each country. 
We run iterated principal factor analysis over a battery of items that deal with women's particularly mothers' - roles in the labor market and the home. They include items on the perceived effects of maternal employment on children and families, ideas about what women want, and ideas about who should earn the money in a family. Overall, they measure the ideological dimension of "maternal employment" well. Cronbach's alpha for the eight items is 0.77 , which indicates that these four items capture one latent, underlying factor; and thus that it makes sense to condense the items into one single variable.

Table 1 shows the summary statistics for the single items and the factor variable, including the question wording and the factor loading. All items are (re)coded such that higher numerical values represent attitudes more supportive of maternal employment. The ensuing factor variable is a continuous measure with a mean of 0 and a range from -2.35 to 1.94. For some of our descriptive analyses, we further split the countries into two country groups: those with values above the mean of the measure, representing the subset of countries with more supportive attitudes toward maternal employment ("more supportive," $\mathrm{N}=18$ ); and those with values below the sample mean, representing the group of countries with less supportive attitudes toward maternal employment ("less supportive," $\mathrm{N}=17$ ). We would like to stress that these groups simply sort countries in those below and above the median of attitudinal support for maternal employment. They don't reflect the simplified construct of the 'egalitarian' or 'essentialist' dimension.

Table 1. Summary table for attitudes toward maternal employment (ISSP micro-level data of respondents from the 35 sample countries). $\mathrm{n}=37,610$.

$\begin{array}{llll}\text { mean } & \text { sd } & \text { range } & \text { histogram } \\ \end{array}$




\begin{tabular}{|c|c|c|c|c|}
\hline & & & & loading \\
\hline $\begin{array}{l}\text { Factor: attitudes toward maternal employment (higher values = } \\
\text { more supportive of maternal employment) }\end{array}$ & 0.00 & 0.90 & $\begin{array}{l}-2.35 \\
1.94\end{array}$ & \\
\hline \multicolumn{5}{|l|}{ Items used to compute the factor: } \\
\hline $\begin{array}{l}\text { Warm relation: A working mother can establish just as warm and } \\
\text { secure a relationship with her children as a mother who does not } \\
\text { work. }^{\text {a }}\end{array}$ & 3.74 & 1.17 & $1 ; 5$ & 0.42 \\
\hline $\begin{array}{l}\text { Child suffers: A pre-school child is likely to suffer if his or her } \\
\text { mother works. }{ }^{\text {b }}\end{array}$ & 3.08 & 1.24 & $1 ; 5$ & -0.69 \\
\hline $\begin{array}{l}\text { Family suffers: All in all, family life suffers when the woman has a } \\
\text { full-time job. }{ }^{\text {b }}\end{array}$ & 3.02 & 1.26 & $1 ; 5$ & -0.69 \\
\hline $\begin{array}{l}\text { Want home: A job is all right, but what most women really want is a } \\
\text { home and children. }{ }^{\text {b }}\end{array}$ & 3.11 & 1.23 & $1 ; 5$ & -0.60 \\
\hline $\begin{array}{l}\text { Housewife: Being a housewife is just as fulfilling as working for } \\
\text { pay. }{ }^{\text {b }}\end{array}$ & 3.13 & 1.20 & $1 ; 5$ & -0.43 \\
\hline $\begin{array}{l}\text { Men money: A man's job is to earn money; a woman's job is to look } \\
\text { after the home and family. }{ }^{\text {b }}\end{array}$ & 2.75 & 1.31 & $1 ; 5$ & -0.68 \\
\hline $\begin{array}{l}\text { Work school: Do you think that women should work outside the } \\
\text { home under the following circumstances? After the youngest child } \\
\text { starts school. }{ }^{\text {c }}\end{array}$ & 0.89 & 0.31 & $0 ; 1$ & 0.37 \\
\hline $\begin{array}{l}\text { Work U6: Do you think that women should work outside the home } \\
\text { under the following circumstances? When there is a child under } \\
\text { school age. }{ }^{c}\end{array}$ & 0.67 & 0.47 & $0 ; 1$ & 0.51 \\
\hline
\end{tabular}

Notes: Weights are applied. Factor loading refers to iterated principal factor analysis.

Answer categories for the first six items: $1=$ strongly disagree; $5=$ strongly agree. For the last two items: 0 $=$ stay at home; $1=$ work part-time or work full-time

School opening status. Information on school closure status is from the UNESCO database "global monitoring of school closures caused by COVID-19" (UNESCO, 2020). This database contains day- and country-specific information on the status of school closures in 210 countries. For most countries, data availability starts in mid to late March; and for all countries, data availability for the status of school closures starts before the date of the maximum lockdown (see below). In the database, school status is available in four categories: (1) most or all schools are closed due to Covid-19; (2) most schools are closed due to an academic break; (3) most schools are partly open; and (4) most schools are fully or almost fully open. The "partly open" group includes cases in which schools are (a) 
“open/closed in certain regions only; and/or (b) open/closed for some grade levels/age groups only; and/or (c) open but with reduced in-person class time, combined with distance learning (hybrid approach)" (UNESCO 2021a). For our main analyses, academic breaks are coded as missing; as a robustness check, breaks are coded as closed. At the peak of the first pandemic phase in late March and early April 2020, schools were shuttered in more than $95 \%$ of all countries worldwide, and in 31 of the 35 sample countries.

Mobility data as a proxy for lockdown intensity. Aggregate data on the change in the amount of time spent in residential areas, compared to a pre-Covid-19 reference period, comes from the Google COVID-19 Community Mobility Reports (Google LLC 2020). This mobility information serves as a control measure for a country's general position on the lockdown-open continuum. Any effective lockdown measure will reduce people's mobility and increase the time they spend at home, so time spent in residential areas is an indication of the general degree of closure or opening of a society. We assume that the less time people spend in residential areas, the greater the degree of societal and institutional openings in this society. Google Mobility Reports are available for 134 countries. The moment of "maximum lockdown" refers to the day when the amount of time spent in residential areas was highest in each country, which occurred, on average, on April 3 (in 30 of the 35 sample countries, the date of maximum lockdown falls within the 15 days between March 25 and April 9).

Infection cases. Information on infection cases is provided by Our World in Data (OWID) (Roser et al. 2020), who draw these data from the European Centre for Disease Prevention 
and Control (ECDC). The numbers refer to daily, new infection cases reported in the respective country, per million inhabitants.

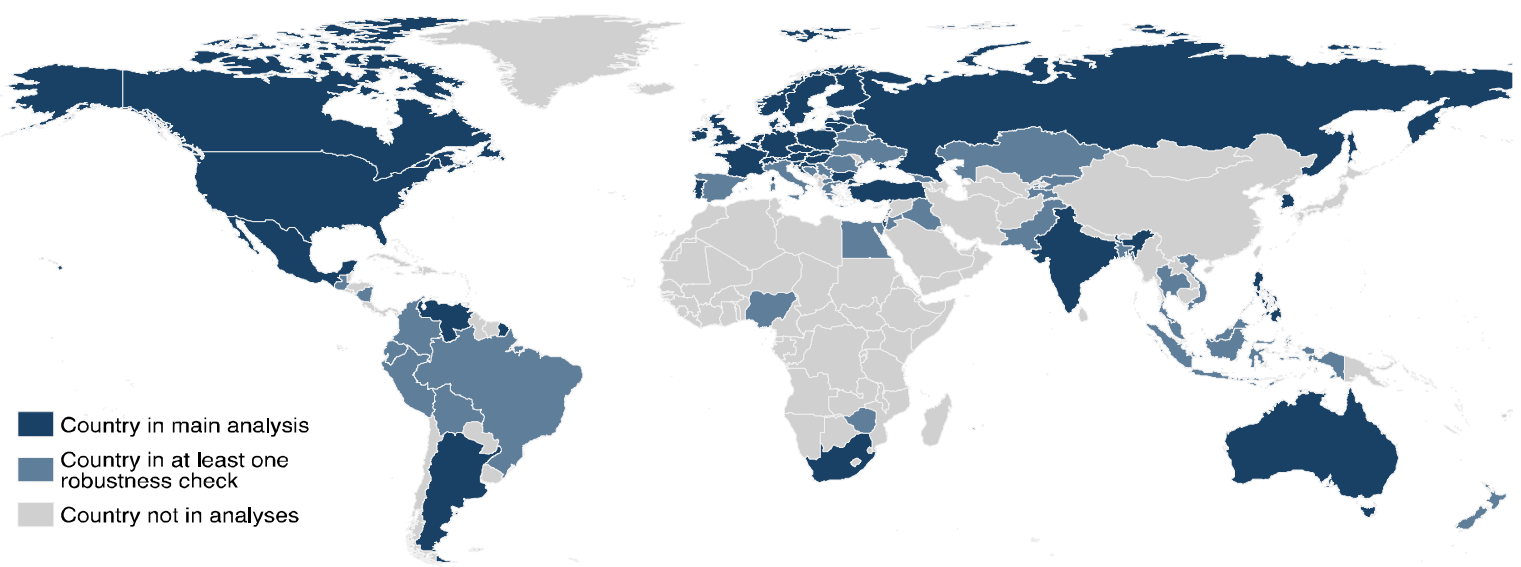

Figure 1. Overview of countries in sample for main analvsis and robustness checks.

\section{Sample selection}

Sample countries. Our theoretical reasoning suggests that gender ideology affects social policy around the globe. Correspondingly, Figure 1 shows that our study covers countries from all continents and world regions. Thus, the sample includes considerable cross-country variation in gender ideology and school opening policies. The main analyses include 35 countries. In total, 69 countries are included in at least one of the robustness checks, some of which use additional data sources to measure gender ideology (see the supplementary material for details). 
The key sample restriction stems from the availability of ISSP data on gender ideology. The ISSP covers 41 countries across the world. Of these, Spain is excluded from the analyses because of measurement inconsistency: in Spain, a four-point scale was used for the first six items displayed in Table 1, instead of the five-point scale used in the other countries. For two countries, China and Iceland, Google Mobility Reports are not available. For Taiwan, information on school openings is not available.

Google Mobility Reports indicate that the countries generally follow the pattern of a clear lockdown peak, followed by a gradual opening. Our analyses are based on such a pattern: we focus on the length of time between the maximum level of the national lockdown in the first months of 2020 (i.e., of the first major lockdown wave) and the subsequent reopening of schools. Two countries diverge substantially from this pattern and are therefore excluded from the sample: Japan and Chile. In the first half of 2020, Japan experienced a first, shorter lockdown phase, followed by a second, longer lockdown phase. The maximum lockdown date observed in the data in early May 2020 was already part of the second lockdown wave. Chile was in an intense and still slightly intensifying lockdown for at least half a year in 2020 , and the maximum lockdown date was reached much later there than in the other countries, at the end of June. This leaves 35 countries from all continents for the main analyses.

Sample period. Our sample period for the regression analyses covers the time from the maximum lockdown date to the first academic break that is at least four weeks long (i.e., the start of the summer holidays and the end of the academic year in most countries in the Northern Hemisphere). In most countries, the summer holidays begin on July 1 (21 
out of the 35 sample countries). The countries with the earliest summer holiday start dates are the Philippines (May 1) and Finland (May 15). The countries with the latest summer holiday start dates are Belgium, Austria, and Mexico (July 11 and August 1). Five countries do not have a longer break during the period of observation (Argentina, Australia, India, South Africa, and South Korea). To keep the sample coherent, we cut these observations off at August 1, the date when the holidays had started in all other countries. On average, the period between the maximum lockdown day and the last sample day was 89 days.

\section{Method}

For our analyses, we use simple descriptive statistics and a panel regression linear probability model (LPM). The descriptive analysis (Figures 1, 2a, and 2b) summarize three school opening statuses over time: (a) most or all schools are closed, (b) schools are partly open, and (c) schools are fully open.

We run panel regression models (daily observations nested in countries) with random effects (random intercept) at the country level. The dependent variable captures whether schools are fully closed or at least partly open. We choose linear probability models over non-linear ones (e.g. probit or logit) because linear models are generally easier to interpret and generally more robust and flexible (Battey, Cox, and Jackson 2019; Mood 2010).

The predictor of interest is time-constant gender ideology, measured as a continuous variable. We are interested in understanding how ideology is associated with changes in school closures as time passes; therefore, ideology is interacted with the time since the maximum lockdown and the squared term of the time since the maximum lockdown. The 
models control for Google Mobility data as proxy for the general lockdown-open continuum, and for daily SARS-CoV-2 infection rates, to ensure that the differences in school reopening schedules based on gender ideology are not driven by differential pandemic activity. The lockdown measure enters as a linear and squared term, infection cases as a linear and logged term.

To reduce the effects of random day-to-day fluctuations (noise), daily infection rates and mobility data are smoothed using local mean smoothing (Gutierrez, Linhart, and Pitblado 2003; Fan and Gijbels 1996). To estimate a smoothed value - for example, infection cases for June 15 in country $\mathrm{X}$ - we define a window around that date; in our case, five days in both directions (June 9-June 20). The algorithm then calculates an average value of these days, whereby June 15 is given the greatest weight, and June 9 and 20 the smallest weight (weighting follows the Epanechnikov distribution). This procedure is repeated for each day: to estimate the value for June 16, another weighted regression is run for the observational window June 10 to June 21, and so forth.

Because of the interaction terms, the estimated coefficients are difficult to interpret from regression tables. Therefore, we plot predicted probabilities of schools reopening by time and by the countries' gender ideology and compare them to the descriptive patterns (Figure 2C). The displayed predictions are based on the day-specific average values of mobility and infection cases. For example, the points for day 40 after the maximum lockdown are not predicted for the grand average value of mobility and infection cases, but for the average mobility and infection data on day 40 over all countries. The attitude measure enters the regression models as a continuous variable. The displayed curves are 
predicted for the average attitude score of the country group less supportive of maternal employment (value of the attitude variable $=-0.34$; displayed in orange) and for the average attitude score of the country group more supportive of maternal employment (value of the attitude variable $=0.36$; purple). This facilitates a direct comparison between the descriptive patterns and model-based predictions. The full regression table and numerous robustness checks are in the supplementary material.

\section{Results}

\section{Impact of gender attitudes on school reopening timing and intensity}

The lines in Figures 1 and 2a show changes in mobility relative to the maximum lockdown day, defined as the day when the maximum amount of time was spent in residential areas across the 35 countries (lines are smoothed). Broadly, all countries follow a similar shape: there was a sharp increase in the amount of time spent at home, followed by a moderate decrease. In all of the figures, purple denotes countries with more supportive attitudes toward maternal employment, and orange denotes countries with less supportive attitudes toward maternal employment. Figures 1 and $2 \mathrm{~A}$ show that the average mobility patterns did not differ between the country groups more supportive and less supportive of maternal employment. However, the average timing of the reopening of schools varied substantially, with school reopenings occurring much sooner after the maximum lockdown date in the more supportive country group. In Figure 1, which tests H1, dots on the single-country mobility lines indicate the day the schools reopened in each country. Country lines without a dot indicate that the country had not yet reopened the schools on the last day of observation. For countries that had never fully closed the schools, the dot is at day zero. 
There are clearly more purple dots, and they are located closer in time to the maximum lockdown date. On average, schools reopened 28 days sooner in the more supportive group, and at $14 \%$ above the average time spent in residential areas, compared with at $8 \%$ in the group less supportive of maternal employment. In other words, the reopening of schools was given a higher priority than other societal reopenings in the countries in the group more supportive of maternal employment, which supports H1.

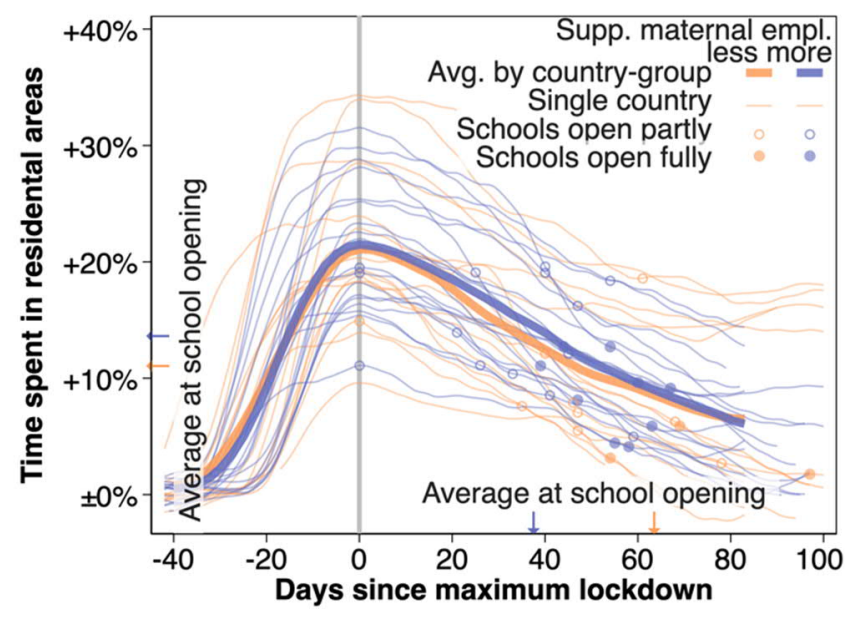

Figure 1. General mobility levels and school openings in single countries and country groups.

Figure $2 \mathrm{~A}$ indicates that 40 days after the maximum lockdown, about half of the countries more supportive of maternal employment, but only about one-quarter of the less supportive countries, had reopened schools, at least in some regions or for some grades. The intensity of school openings also varied by gender ideology: 80 days after the maximum lockdown, schools were fully reopened in about $45 \%$ of the more supportive countries, but in less than $10 \%$ of the societies less supportive of maternal employment (Figure 2A), which supports $\mathrm{H} 2$.

Figure 2B shows a scatterplot of the timing of school reopenings and the factor value 
(continuous measure) for ideology on maternal employment for all countries. A significant linear trend is present: an ideology more supportive of maternal employment correlates with faster school reopenings $(r=-.42)$, which again supports H1. Several countries had not yet reopened the schools before the first day of summer break, and most of these countries are in the less supportive group. Some of the countries with schools that were still closed at the last observation are in the Americas, where the lockdowns started sooner relative to the SARS-CoV-2 infection peak. Therefore, further testing of whether the association between gender ideology and school reopenings holds when controlling for infectious activity is necessary.

Figure 2C shows model-based predicted values of school openings by ideological group, net of country-specific SARS-CoV-2 infection rates and residential mobility levels (dashed lines with confidence interval bands). The figure shows that the model-based predictions generally correspond well to the observed opening rates (solid lines). During the two weeks immediately after the maximum lockdown, schools were closed in most countries and predicted school closure probabilities did not vary significantly between the two groups. Thereafter, school reopenings occurred significantly faster in the country group more supportive of maternal employment, mainly 20-70 days after the maximum lockdown date, which indicates that the descriptive pattern holds. 


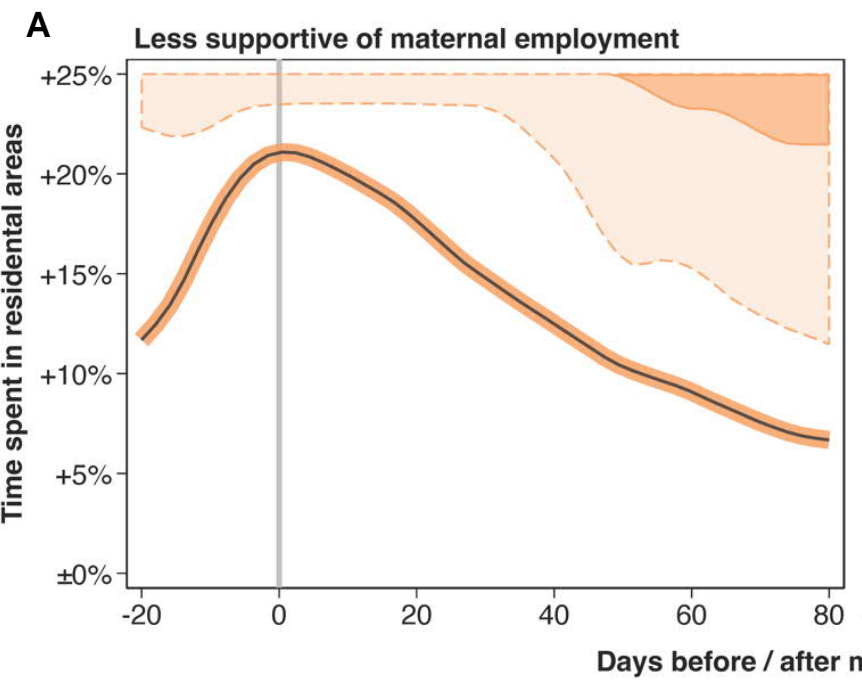

More supportive of maternal employment
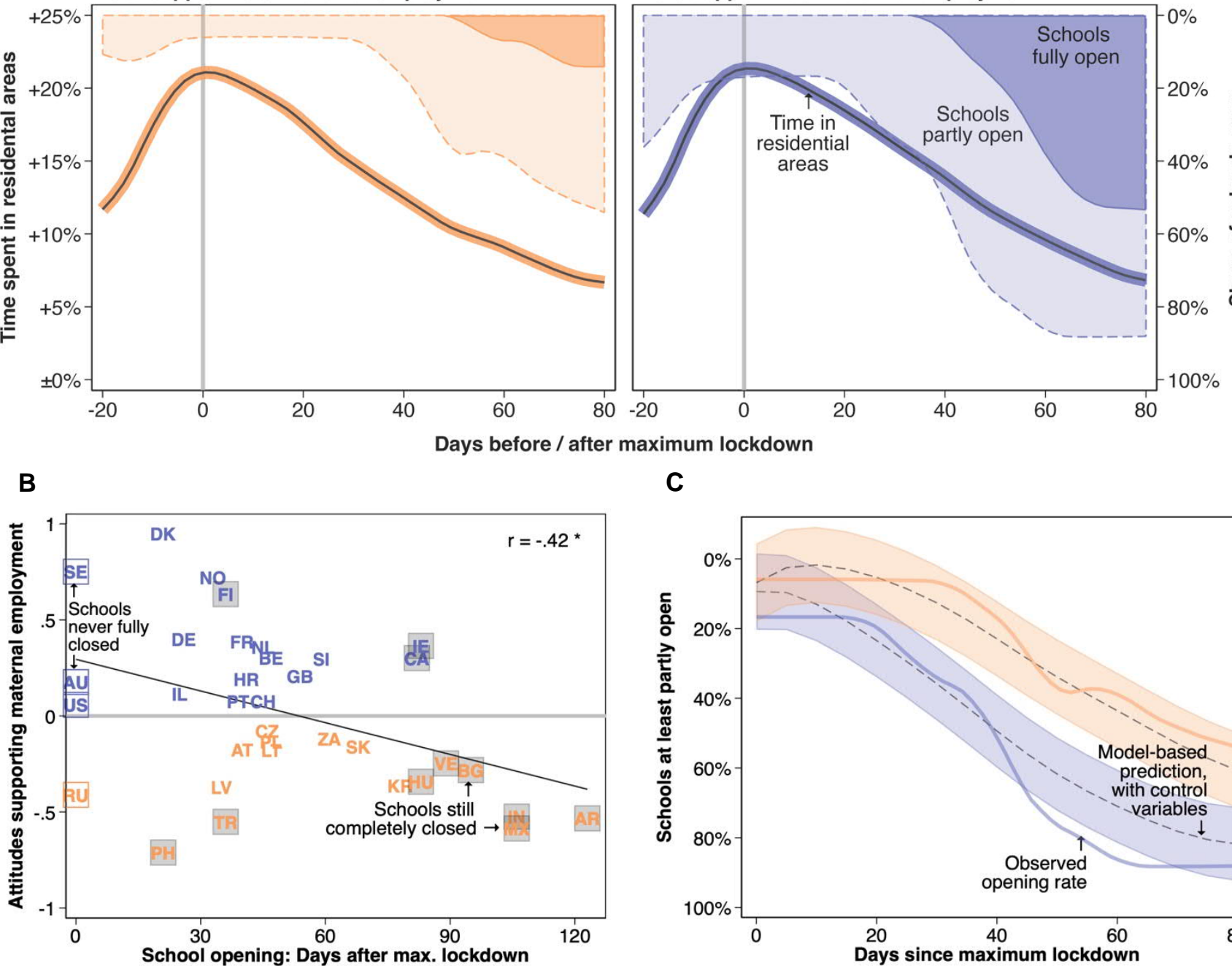

C



Figure 2. Panel A: Trajectories concerning general mobility and school openings in countries that are less supportive of maternal employment, and in countries that are more supportive of maternal employment. Panel B: Bivariate association between the maximum lockdown date and the reopening of schools in the country against the continuous ideology measure. Panel C: Actual school opening trajectories of countries less and more supportive of maternal employment compared to model-based predictions (panel regression model that predicts school openings based on gender ideology, interacted with days since the maximum lockdown date, controlling for general mobility levels and infection cases). The regression table can be found in the supplementary material, Table S3. 


\section{Robustness checks and further analyses}

We conducted several additional analyses and robustness checks, most of which can be found in the supplementary material.

\section{Different codings}

To test whether our results depend on a certain coding of school opening status, we test two alternative codings. The coding for the main analyses compares "most or all schools closed" (=0) with schools that are at least partly open $(=1)$. The first alternative moves "partly open" to the zero category, and compares schools that are fully or partly closed (0) with schools that are fully or almost fully open. The second alternative makes use of all of the available information on school openings. The variable is coded 0 if all of the schools in the country are closed, 0.5 if the schools are partly open, and 1 if the schools are fully open. Figure 3 shows that the results for these alternative outcome variables are consistent: a gender ideology more supportive of maternal employment has a substantial positive effect on school reopenings. This analysis provides further support for $\mathrm{H} 2$ : countries that are more supportive of maternal employment not only reopened the schools more quickly, but also at greater intensities. 

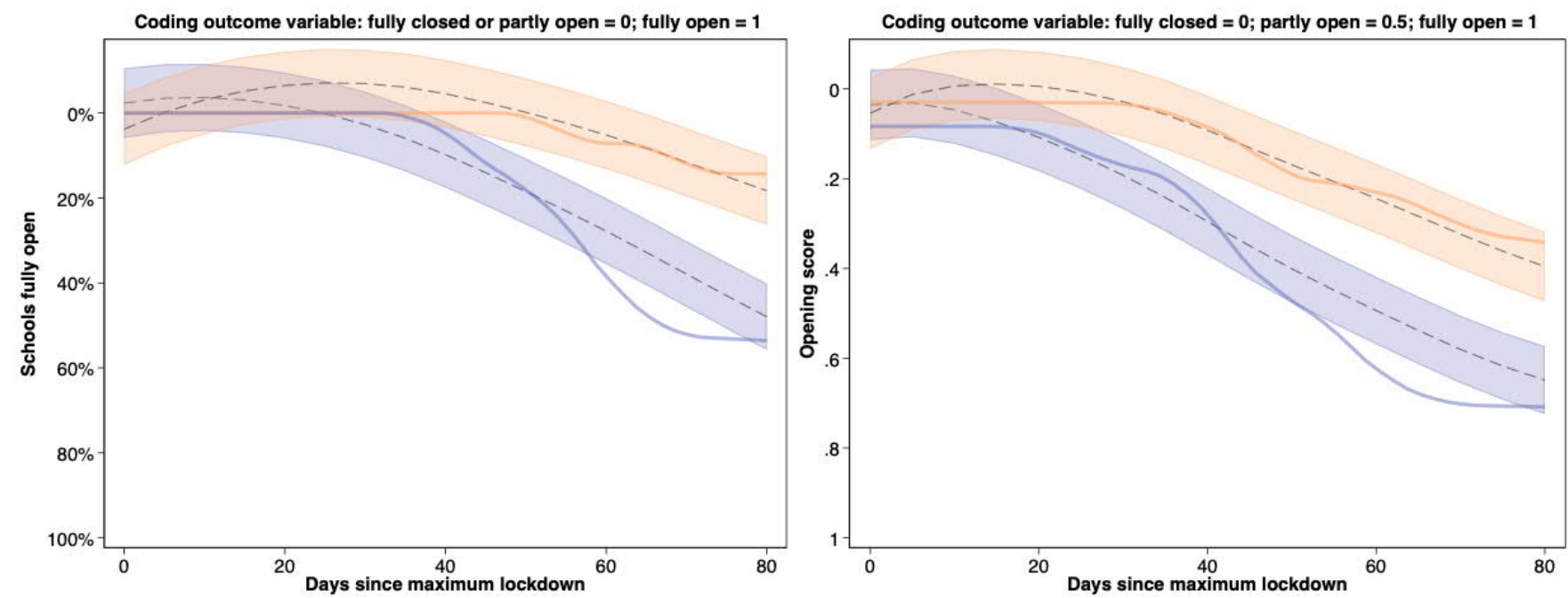

Figure 3. Alternative codings of school opening status. Actual school opening trajectories of countries less and more supportive of maternal employment compared to model-based predictions (panel regression model that predicts school openings based on gender ideology, interacted with days since the maximum lockdown day, controlling for general mobility levels and infection cases).

\section{Survival analysis}

Second, we apply a different modeling strategy and study school reopenings using survival analysis. These analyses test whether gender ideology affects time-to-event and the school reopening rate (hazard rate). However, using survival analysis, the analytical sample decreases because (a) we can only study countries that were closed at the maximum lockdown date (which is the case for 31 out of the 35 countries in our main sample), and (b) because countries leave the sample after the schools reopened (in South Africa, schools were reopened in early June and were closed again shortly thereafter; the survival-analysis sample cuts off at the first reopening). Table 2 shows the results for this alternative modeling strategy. The effect of gender ideology is highly significant, and a one-point increase in the standardized attitudes measure reduces the predicted time between the maximum lockdown date and the reopening of the schools by around a third. 
Table 2. Parametric survival analysis, log-logistic survival distribution. Sub-sample: all countries where schools were closed at the maximum lockdown date.

\begin{tabular}{lll}
\hline & \multicolumn{2}{l}{ Survival analysis } \\
\hline Attitudes (higher = more supportive of maternal empl.) & $0.657^{* * *}$ & $(0.0785)$ \\
Time spent in residential areas & 1.192 & $(0.168)$ \\
Time spent in residential areas ${ }^{2}$ & 0.996 & $(0.00399)$ \\
Infection cases & 1.038 & $(0.0206)$ \\
Infection cases, logged & 0.545 & $(0.190)$ \\
\hline Observations: countries & 31 & \\
Number of failures (= school openings) & 20 & \\
Time at risk: countries X days & 1756 &
\end{tabular}

Exponentiated coefficients displayed (e.g., the value of 0.657 for attitudes shows that an increase in the attitudes measure reduced the predicted time to school reopening by $34.3 \%$ ).

$t$ statistics in parentheses. ${ }^{*} p<0.05,{ }^{* *} p<0.01,{ }^{* * *} p<0.001$

Infection cases and time spent in residential areas are smoothed using local linear smoothing.

\section{Alternative gender ideology measures}

First, to test the robustness of our attitudinal measure, we replicated our main model using the single attitudinal items from the ISSP 2012 instead of the factor variable, which yields robust results $\left(\mathrm{n}_{\text {countries }}=35\right)$.

Second, we utilized an alternative source of attitudinal data, the European/World Value Surveys (EVS/WVS, Wave 2017-2020), to replicate a subset of the analysis using a larger sample of countries ( $\left.\mathrm{n}_{\text {countries }}=61\right)$. The EVS/WVS cover more countries, but have fewer suitable attitudinal items. However, there is one item that is included in both the ISSP and the latest wave of the WVS/EVS. The findings of the regression model that includes this item and the larger sample of countries confirm our main result. 
Fourth, we tested for alternative explanations related to the countries' resources and readiness to "pandemic-proof" schools, to organize digital distance learning, and to respond to a health emergency; and to the countries' age structures. We controlled for a country's GDP; social spending measured as the share of GDP spent on social expenditures; degree of digitalization measured using the Digital Adoption Index by the World Bank; and health care system capacity measured using the Global Health Security Index (GHS) by the Johns Hopkins Center for Health Security, the Nuclear Threat Initiative (NTI), and the Economist Intelligence Unit (EIU) (separate models). We used a measure for the median population age to control for age structure, because countries with older populations are more vulnerable to severe SARS-CoV-2 cases. Our findings are robust to controlling for either of these factors.

Fifth, we examined the timing of school holidays and an alternative coding of academic breaks. We control for the time between the maximum lockdown date and the beginning of the first longer academic break (summer holidays in the Northern Hemisphere) because, for example, countries with an earlier summer break may have opened schools sooner to provide students with at least some time in school before the start of the summer break. Further, we test coding summer breaks as "closed" instead of cutting the observations off, because countries may have deliberately delayed school holidays due to the pandemic situation. The main effect remains robust in these models.

Sixth, we examined whether "lived" gender roles, measured as maternal employment rates, affected school reopening schedules, rather than ideal gender roles. Policy-makers in the less supportive countries may have perceived school closures as less costly because of the 
lower maternal employment rates in these societies - which might be an accurate assessment if only direct economic costs are taken into account. Moreover, maternal employment rates are indeed associated with gender ideology, and are therefore important to take into account as a potential confounder (Budig, Misra, and Boeckmann 2012; Ruppanner, Collins, et al. 2021). However, while the groups of countries differ in terms of the employment rates of mothers of very young children (under school age), the average employment rates of mothers of school-aged children (aged 6-14) are very similar (74\% in less supportive countries vs. $77 \%$ in countries more supportive of maternal employment). Controlling for the employment rates of mothers with school-aged children does not change our findings. This supports the claim that decision-making was indeed driven by bias and not by an accurate assessment of the economic costs of school closures.

Seventh, we also tested for alternative cultural-attitudinal explanations. Gender ideology may be correlated with attitudes toward children, such as childrearing values or attitudes about adherence to social norms. Recent research has shown that nations that are culturally "tight" - i.e., that strictly control and demand adherence to social norms - had significantly fewer Covid-19 cases and deaths (Gelfand et al. 2021). Thus, if gender ideology is correlated with conformity values or cultural "tightness," the effect of gender ideology on school closure policies may be spurious. We therefore controlled for two indices that capture these dimensions, childrearing values (Tillman 2013) and cultural "tightness" (Eriksson et al. 2021), and our main findings remained robust, which further underscores our assumption that gender ideology had an effect on school closure durations that was independent of other cultural framings. 
Finally, we conducted a placebo test and estimated the effect of gender ideology on the reopening pace of other containment measures, using the Oxford Covid-19 government response tracker. We computed an index of all government containment responses, except for the closure of educational facilities. We found that the attitudes toward maternal employment did not predict the lifting of the other containment measures. This result further underscores our claim that gender ideology bias influenced school-related pandemic policies, which has far-reaching gendered implications; but did not influence other containment measures, the consequences of which are less gendered.

\section{Discussion and conclusions}

Across the world, school closures and home schooling have become commonly used, yet highly debated Covid-19 pandemic containment measures. Two years into the pandemic, it is well-documented that school closures are associated with a wide array of adverse consequences for children, adolescents, and families, and that they have exacerbated social and gender inequalities. At the same time, conclusive scientific evidence on the overall development of SARS-CoV-2 transmission rates in a given country depending on whether the schools were open or closed, isolated from other measures, is still lacking; as are clearcut criteria for determining whether, and, if so, when schools should have been shuttered to slow transmission (Heavey et al. 2020; Kim et al. 2020; Stein-Zamir et al. 2020; Li et al. 2020; Macartney et al. 2020; Abdollahi et al. 2020; Behörde für Schule und Berufsbildung 2020; Lee and Raszka 2020; Ehrhardt et al. 2020; Auger et al. 2020; Walsh et al. 2021). Moreover, little is known about whether school closures are effective in 
slowing transmission - if they are effective at all - because they restrict children's mobility or because they decrease parents' mobility. Unfortunately, such evidence is not easy to come by and will likely remain missing for some time, if not forever. Collecting such data would involve tracing transmission chains in schools, families, and communities, differentiated by adults and children, children's ages, and the hygiene and distancing measures practiced inside and outside of schools. Obtaining such evidence would also involve gathering in-depth information on children's and parents' whereabouts, caregiver arrangements, and social contacts when schools are closed; particularly in cases of extended school closures, during which (working) parents may have exhausted the time, financial, and emotional resources needed for home-based care and schooling. A stagnation or even an increase in SARS-CoV-2 transmission in the public and private realm may well occur when children are moved from controlled school settings to potentially less wellsupervised and less-regulated private settings, because they will likely continue to have social contact, including increased contact with the elderly (Brooks et al. 2020). Indeed, a tracing study from Austria, which developed one of the most comprehensive testing programs for SARS-CoV-2 infections among school-aged children, demonstrated that around $90 \%$ of transmission clusters occurred in households and private or health-related social settings. In comparison, only about $2.5 \%$ occurred in school settings during the first half of November 2020, when schools were fully open (AGES - Österreichische Agentur für Gesundheit und Ernährungssicherheit GmbH 2020; Willeit et al. 2021). While evidence on SARS-CoV-2 transmission in schools is rapidly emerging, there has been little research on changes in family- and community-based SARS-CoV-2 transmission rates due to shuttered schools. Thus, policy-makers lack clear guidance on how to coordinate school- 
related decision-making with pandemic containment efforts. To complicate the picture, the debate about whether evidence from in-school transmission studies should be evaluated in terms of the absolute numbers, or relative to the rates of the spread of the virus in the surrounding communities; and the debate about how much school-based SARS-CoV-2 transmission justifies closing schools in light of the many negative mental health, educational, and social consequences of doing so; are nowhere near settled (Oster 2020). It has, however, become evident that Covid-19 infections in children are often mild and that for children, the risk of developing a severe case of the disease is very low (Sinha et al. 2020; Snape and Viner 2020; Zimmermann, Pittet, and Curtis 2021; Kostoff et al. 2021).

In the absence of such clear epidemiological guidance, policy-makers' decisions about how to manage schools during the pandemic have been based on their own judgments. Indeed, emerging research suggests that policy-makers have largely relied on ideational factors for making decisions related to the management of schools in the pandemic. For instance, leaders across Europe may have been guided by their political goal-priority mixes, such as whether their pandemic containment strategies focused on work-family balance, education, or social inequality prevention (Blum and Dobrotić 2020). In addition, partisanship and the strength of teachers' unions likely drove school reopening decisions across US school districts in the fall of 2020, while SARS-CoV-2 infection rates did not (Hartney and Finger 2020).

Our study demonstrated that societal gender role attitudes represent another important ideational aspect that affected the pace and the intensity of school reopenings after the first wave of Covid-19 lockdowns around the world. We found strong and robust evidence that 
gender attitudes influenced school reopening schedules: i.e., the higher the attitudinal support for maternal employment, the sooner the schools reopened, and the more likely they were to be fully reopened, instead of only partially or regionally.

One of our contributions is theoretical. We bridged literatures that theorize ideas in policymaking, offer feminist perspectives on the gender-social policy nexus, and concern gender ideology. Drawing from Beland (2009) and Swinkels (2020), we extended previous conceptualizations by arguing that the what, or the content of an idea, needs to be differentiated from the how, i.e., the horizontal axis of the process of influence; and the via whom, i.e., the vertical axis or the societal level of influence on which it operates. Concerning the via whom or the vertical axis, we hypothesized that gender role attitudes affected school operations at the individual level via cognitive heuristics and gender ideology bias among policy-makers; and via gender ideology normative framing, or normative guiding principles, at the institutional level. Regarding the procedural how, or horizontal axis, we hypothesized that these two mechanisms affected school operational policy-making in two steps: first, whether shuttered schools were perceived as an immediate problem in need of alleviation (school reopening pace); and, second, the specific reopening policies that were applied once schools were reopened (school reopening intensity).

Another contribution of our study is its rigorous empirical design in assessing the effect of ideas on policy-making. The common shock of worldwide school closures in March 2020, coupled with lacking scientific guidance on schools' epidemiological role and the high overall level of uncertainty, created near-ideal circumstances for testing the influence of 
ideas on school reopening policies. Thus, despite the limitations and threats to causal inference, our study offers generalizable evidence of an effect of ideas on policy-making.

Prior classical scholarship on ideational influences on policy-making largely ignored ideas about gender (Beland 2009). Instead, feminist research has developed its own set of theories about how gendered ideation shapes and is shaped by states and political processes, and contributes to the reproduction of inequalities (Brush 2003). This research has convincingly argued that ideas about gendered societal roles need to be included in the examination of ideas about policy-making. Our study has brought these literatures together and has shown that there is considerable potential for synergies going forward. These synergies may be particularly relevant in times when gender and social inequalities are growing, such as during and after the Covid-19 pandemic.

During the first wave of lockdowns, the gendered consequences of the school closures were not yet systematically documented. However, predictions issued during the first lockdowns that gender inequality would increase as a result of the pandemic turned out to be correct. Recent studies have shown that while fathers have been doing more domestic work and childcare during the lockdowns than they were before the pandemic, substantial gender imbalances in the division of work at the expense of mothers have remained or have widened during the pandemic, and have led to even larger gender gaps in absolute contributions to domestic and care work in many societies (Götzinger et al. 2020; Farré et al. 2020; Yildirim and Eslen-Ziya 2021; Hank and Steinbach 2021; Craig and Churchill 2021; Del Boca et al. 2020; Hipp and Bünning 2020; Meraviglia and Dudka 2021; Shafer, Milkie, and Scheibling 2020; Fodor et al. 2020). In addition, more mothers than fathers 
have lost their employment or reduced their work hours during the pandemic (Alon et al. 2020). Perhaps most importantly, the body of evidence on the harm to children as a consequence of school closures and lockdowns has been growing, and points to the emergence of generational inequalities (The World Bank, UNESCO, and UNICEF 2021; Russell Viner, Bonell, et al. 2022; Russell Viner, Russell, et al. 2022). In other words, gender ideology normative framing and gender ideology bias led to extended school closures that are expected to have profound social and gendered consequences, and to leave their mark on societies for years to come.

Our study has limitations. First, we assume that our measures for average societal gender attitudes represent well the attitudes of policy-makers, or at least the ideas they were drawing upon in their decision-making. However, in this study, we were not able to trace this gender ideology bias at the individual level. While we can measure the effect of a society's average attitude toward maternal employment on the timing and intensity of school reopenings on the country level, we cannot verify or falsify whether this observed relation operates indeed via gender ideology bias among individuals, gender ideology normative framings on the institutional level, both, or other pathways. Hence, while we can test the horizontal how of the ideational process, we need to leave the assessment of the exact who, or social level, or vertical axis of the influential process open to be examined by future research.

Second, and similarly, there may be additional vertical pathways via which gender ideational and other ideational influences may affect school-related policymaking. These may differ across the countries we study. For instance, education jurisdiction is situated at 
the local or federal state level in some countries, and centralized in others (OECD 2021). Our argument rests on the assumption that school operations between March and July 2020 were decided rather rapidly and by the executive, potentially guided by expert task forces. That is, policy-making happened without the involvement of diverse actors, interest groups, or a broad public discourse. We cannot test this assumption for a diverse set of countries, but we can illustrate that it seems to hold for two countries that we are familiar with, Germany and the US. In Germany, the national academy of sciences 'Leopoldina' issued a statement with specific suggestions for the reopening phase on April 132020 , based on the recommendations of a group of 34 senior scientists (Leopoldina 2020). These suggestions were used as a blueprint for the common agreement between Chancellor Angela Merkel and the Federal Prime Ministers two days later, and the subsequent implementation in all federal states (Luig 2020; Der Spiegel 2020; Vogt 2020). In the US, governors decided on school status during our study period (Marianno 2021). Other interest groups at the local level, such as unions, became supposedly relevant for decision-making on school operations only in subsequent phases of the pandemic (Goldstein and Scheiber 2022; Marianno 2021; Grossmann et al. 2021). Nonetheless, it is beyond the scope of this study to examine the exact actors and vertical pathways of school operation decisionmaking following first school closures in 2020 in all countries. Future research is needed to reconstruct and examine school-operation-related decision-making during the pandemic, with deeper investigation into relevant actors, their positions and biases, their discursive processes, and how the mix of relevant elements has varied throughout the pandemic. Studies employing qualitative methodology would be especially well-suited.

Third, we excluded an array of plausible alternative explanations and factors that may have 
mediated the effects of ideology on school reopening schedules. However, in the absence of randomized treatments, our observational study estimated the effects of gender ideology on school reopenings using methods that rested on the assumption that no omitted-variable bias was present. In other words, we could not be certain that other unobserved factors that were caused by or strongly correlated with gender ideology did not drive our findings, or pose a threat to causal inference. For instance, while we could exclude the possibility that the gender ideology effect was driven by childrearing values, employment rates of mothers, and rule adherence norms; we could not exclude the possibility that other cultural factors ultimately drove both gender ideology and the prioritization of school reopenings.

Fourth, while we showed the relevance of gender ideology and the likely existence of a gender ideology bias in policy decision-making regarding the management of schools during a pandemic, our findings are not necessarily generalizable to non-pandemic periods, when policy-makers are likely to have more time and to experience less pressure when making decisions. Finally, political leaders in different countries may have communicated with and influenced each other during the first lockdowns, which might imply that our study does not meet the "stable unit treatment value assumption" of causal inference, which implies that there is no interference between units; i.e., that they react independently from one another (Rubin 1980; Gangl 2010).

To close, the results of our study suggest that gender ideation played an important role in school closure policy decision-making in the Covid-19 pandemic. Much is at stake for the future of societies when the well-being, mental health, and educational prospects of children, as well as gender and social inequality, are compromised due to shuttered schools. 
Prior research has shown that how long a specific policy is maintained despite emerging evidence of its ineffectiveness or even detrimental consequences can be a function of strong ideas (Matthijs 2016, 384). Therefore, despite their limitations, our results offer an important self-reflection tool for individuals in decision-making positions, urging them to consider their potentially hidden gender role ideation and assumptions about mothers' roles before making far-reaching decisions to close schools. Our findings also imply that countries with unequal gender role ideals more readily implemented pandemic containment measures that compromised gender equality, which likely implies that the losses in women's empowerment during the pandemic have been steeper in societies that were less gender-equal to begin with. 


\section{References}

Abdollahi, Elaheh, Margaret Haworth-Brockman, Yoav Keynan, Joanne M Langley, and Seyed M Moghadas. 2020. 'Simulating the Effect of School Closure during COVID-19 Outbreaks in Ontario, Canada'. BMC Medicine 18 (1): 1-8.

Adams, J., and T. Padamsee. 2001. 'Signs and Regimes: Rereading Feminist Work on Welfare States'. Social Politics: International Studies in Gender, State \& Society 8 (1): 1-23. https://doi.org/10.1093/sp/8.1.1.

AGES - Österreichische Agentur für Gesundheit und Ernährungssicherheit GmbH. 2020. 'Epidemiologische Abklärung Covid 19'.

Alon, Titan, Matthias Doepke, Jane Olmstead-Rumsey, and Michèle Tertilt. 2020. 'This Time It's Different: The Role of Women's Employment in a Pandemic Recession'. National Bureau of Economic Research.

Alonso-Martínez, Alicia M., Robinson Ramírez-Vélez, Yesenia García-Alonso, Mikel Izquierdo, and Antonio García-Hermoso. 2021. 'Physical Activity, Sedentary Behavior, Sleep and SelfRegulation in Spanish Preschoolers during the COVID-19 Lockdown'. International Journal of Environmental Research and Public Health 18 (2): 693. https://doi.org/10.3390/ijerph18020693.

Andrew, Alison, Sarah Cattan, Monica Costa Dias, Christine Farquharson, Lucy Kraftman, Sonya Krutikova, Angus Phimister, and Almudena Sevilla. 2020. 'How Are Mothers and Fathers Balancing Work and Family under Lockdown?' 27 May 2020. https://doi.org/10.1920/BN.IFS.2020.BN0290.

Auger, Katherine A, Samir S Shah, Troy Richardson, David Hartley, Matthew Hall, Amanda Warniment, Kristen Timmons, Dianna Bosse, Sarah A Ferris, and Patrick W Brady. 2020. 'Association between Statewide School Closure and COVID-19 Incidence and Mortality in the US'. Jama 324 (9): 859-70.

Battey, Heather S, David R Cox, and Michelle V Jackson. 2019. 'On the Linear in Probability Model for Binary Data'. Royal Society Open Science 6 (5): 190067.

Behörde für Schule und Berufsbildung. 2020. 'Hamburgs Schülerinnen Und Schüler Infizierten Sich Außerhalb Der Schule Offensichtlich Vier Mal so Häufig Wie in Der Schule'.

Béland, Daniel. 2009. 'Gender, Ideational Analysis, and Social Policy'. Social Politics: International Studies in Gender, State \& Society 16 (4): 558-81. https://doi.org/10.1093/sp/jxp017.

. 2016. 'Ideas and Institutions in Social Policy Research'. Social Policy \& Administration 50 (6): 734-50. https://doi.org/10.1111/spol.12258.

Béland, Daniel, Bea Cantillon, Rod Hick, and Amílcar Moreira. 2021. 'Social Policy in the Face of a Global Pandemic: Policy Responses to the COVID -19 Crisis'. Social Policy \& Administration 55 (2): 249-60. https://doi.org/10.1111/spol.12718.

Béland, Daniel, and Robert Henry Cox. 2010. Ideas and Politics in Social Science Research. Oxford University Press. 
Bianchi, Suzanne M, Liana C Sayer, Melissa A Milkie, and John P Robinson. 2012. 'Housework: Who Did, Does or Will Do It, and How Much Does It Matter?' Social Forces 91 (1): 55-63.

Block, Katharina, Alyssa Croft, and Toni Schmader. 2018. 'Worth Less?: Why Men (and Women) Devalue Care-Oriented Careers'. Frontiers in Psychology 9.

https://www.frontiersin.org/article/10.3389/fpsyg.2018.01353.

Blum, Sonja, and Ivana Dobrotić. 2020. 'Childcare-Policy Responses in the COVID-19

Pandemic: Unpacking Cross-Country Variation'. European Societies, 1-19.

Blyth, Mark. 2001. 'The Transformation of the Swedish Model: Economic Ideas, Distributional Conflict, and Institutional Change'. World Politics 54 (1): 1-26.

https://doi.org/10.1353/wp.2001.0020.

Boca, Daniela Del, Noemi Oggero, Paola Profeta, and Maria Christina Rossi. 2021. 'Did COVID19 Affect the Division of Labor within the Household? Evidence from Two Waves of the Pandemic in Italy'. SSRN Scholarly Paper ID 3863828. Rochester, NY: Social Science Research Network. https://doi.org/10.2139/ssrn.3863828.

Brooks, Samantha K, Louise E Smith, Rebecca K Webster, Dale Weston, Lisa Woodland, Ian Hall, and G James Rubin. 2020. 'The Impact of Unplanned School Closure on Children's Social Contact: Rapid Evidence Review’. Eurosurveillance 25 (13): 2000188.

Brush, Lisa D. 2003. Gender and Governance. Rowman Altamira.

Budig, Michelle J, Joya Misra, and Irene Boeckmann. 2012. 'The Motherhood Penalty in CrossNational Perspective: The Importance of Work-Family Policies and Cultural Attitudes'. Social Politics 19 (2): 163-93.

Burbio. 2022. 'K-12 School Opening Tracker'. 2022. https://cai.burbio.com/school-openingtracker/.

Burkart, Sarah, Hannah Parker, R. Glenn Weaver, Michael W. Beets, Alexis Jones, Elizabeth L. Adams, Jean-Philippe Chaput, and Bridget Armstrong. 2022. 'Impact of the COVID-19 Pandemic on Elementary Schoolers' Physical Activity, Sleep, Screen Time and Diet: A QuasiExperimental Interrupted Time Series Study'. Pediatric Obesity 17 (1): e12846. https://doi.org/10.1111/ijpo.12846.

Cairney, Paul. 2019. Understanding Public Policy: Theories and Issues. Bloomsbury Publishing.

Calarco, Jessica McCrory, Elizabeth Anderson, Emily Meanwell, and Amelia Knopf. 2020. "'Let's Not Pretend It's Fun": How COVID-19-Related School and Childcare Closures Are Damaging Mothers' Well-Being'.

Campbell, John L. 2002. 'Ideas, Politics, and Public Policy'. Annual Review of Sociology 28 (1): 21-38.

Campbell, John L. 2008. 'What Do We Know—or Not—about Ideas and Politics'. Institutions and Politics Eds. Peter Nedergaard and John Campbell, 157-76.

Carlson, Daniel L., Richard J. Petts, and Joanna R. Pepin. 2021. 'Changes in US Parents' Domestic Labor During the Early Days of the COVID-19 Pandemic'. Sociological Inquiry. 
https://doi.org/10.1111/soin.12459.

Carson, Andrea, Leah Ruppanner, and Shaun Ratcliff. 2020. 'The Worsening of Australian Women's Experiences under COVID-19: A Crisis for Victoria's Future'.

Charles, Maria, and David B Grusky. 2005. Occupational Ghettos: The Worldwide Segregation of Women and Men. Vol. 200. Stanford University Press Stanford, CA.

Chung, Heejung, Holly Birkett, Sarah Forbes, and Hyojin Seo. 2021. 'Covid-19, Flexible Working, and Implications for Gender Equality in the United Kingdom'. Gender \& Society 35 (2): 218-32. https://doi.org/10.1177/08912432211001304.

Collins, Caitlyn, Liana Christin Landivar, Leah Ruppanner, and William J Scarborough. 2021. 'COVID-19 and the Gender Gap in Work Hours'. Gender, Work \& Organization 28 (S1): 10112.

Craig, Lyn, and Brendan Churchill. 2021. 'Dual-earner Parent Couples' Work and Care during COVID-19'. Gender, Work \& Organization 28 (S1): 66-79.

Davis, Shannon N., and Theodore N. Greenstein. 2004. 'Interactive Effects of Gender Ideology and Age at First Marriage on Women's Marital Disruption'. Journal of Family Issues 25 (5): 658-82. https://doi.org/10.1177/0192513X03257795.

- 2009. 'Gender Ideology: Components, Predictors, and Consequences'. Annual Review of Sociology 35 (1): 87-105. https://doi.org/10.1146/annurev-soc-070308-115920.

Del Boca, Daniela, Noemi Oggero, Paola Profeta, and Mariacristina Rossi. 2020. 'Women's and Men's Work, Housework and Childcare, before and during COVID-19'. Review of Economics of the Household 18 (4): 1001-17. https://doi.org/10.1007/s11150-020-09502-1.

Der Spiegel. 2020. 'Leopoldina-Forscher halten Schulöffnungen für möglich - doch nur für einen Teil der Schüler.', 10 April 2020, sec. Wissenschaft. https://www.spiegel.de/wissenschaft/coronakrise-leopoldina-forscher-halten-schuloeffnungen-fuer-aeltere-schueler-fuer-moeglich-afcfd3dfa-c442-488d-9ab1-2bd21bb7ad3f.

Dias, Felipe A, Joseph Chance, and Arianna Buchanan. 2020. 'The Motherhood Penalty and the Fatherhood Premium in Employment during Covid-19: Evidence from the United States'.

Research in Social Stratification and Mobility 69: 100542.

Donnelly, Robin, and Harry Anthony Patrinos. 2021. 'Learning Loss during Covid-19: An Early Systematic Review'. PROSPECTS, November. https://doi.org/10.1007/s11125-021-09582-6.

Ehrhardt, J, A Ekinci, H Krehl, M Meincke, I Finci, J Klein, B Geisel, C Wagner-Wiening, M Eichner, and S O Brockmann. 2020. 'Transmission of SARS-CoV-2 in Children Aged 0 to 19 Years in Childcare Facilities and Schools after Their Reopening in May 2020, BadenWürttemberg, Germany'. Eurosurveillance 25 (36): 2001587.

Engel, Christoph. 2016. 'A Random Shock Is Not Random Assignment'. Economics Letters 145: 45-47. https://doi.org/10.1016/j.econlet.2016.05.022.

England, Paula. 2005. 'Emerging Theories of Care Work'. Annual Review of Sociology 31 (1): 381-99. https://doi.org/10.1146/annurev.soc.31.041304.122317. 
Engzell, Per, Arun Frey, and Mark D. Verhagen. 2021. 'Learning Loss Due to School Closures during the COVID-19 Pandemic'. Proceedings of the National Academy of Sciences 118 (17). https://doi.org/10.1073/pnas.2022376118.

Eriksson, K., P. Strimling, M. Gelfand, J. Wu, J. Abernathy, C. S. Akotia, A. R. Dorrough, A. Glöckner, and P. A. M. Van Lange. 2021. 'Perceptions of the Appropriate Response to Norm Violation in 57 Societies'. Nature Communications 12 (1481).

Esping-Andersen, Gosta. 1999. Social Foundations of Postindustrial Economies. OUP Oxford.

Fan, J., and I. Gijbels. 1996. Local Polynomial Modelling and Its Applications. London: Chapman and Hall.

Farre, Lidia, Yarine Fawaz, Libertad Gonzalez, and Jennifer Graves. 2020. 'Farré et al. (2020): How the Covid-19 Lockdown Affected Gender Inequality in Paid and Unpaid Work in Spain'. SSRN Electronic Journal. https://doi.org/10.2139/ssrn.3643198.

Farré, Lídia, Yarine Fawaz, Libertad González, and Jennifer Graves. 2020. 'How the COVID-19 Lockdown Affected Gender Inequality in Paid and Unpaid Work in Spain'.

Fodor, Éva, Anikó Gregor, Júlia Koltai, and Eszter Kováts. 2020. 'The Impact of COVID-19 on the Gender Division of Childcare Work in Hungary'. European Societies 23 (Sup1): S95-110.

Frank, Elena, Zhuo Zhao, Yu Fang, Lisa S. Rotenstein, Srijan Sen, and Constance Guille. 2021. 'Experiences of Work-Family Conflict and Mental Health Symptoms by Gender Among Physician Parents During the COVID-19 Pandemic'. JAMA Network Open 4 (11): e2134315. https://doi.org/10.1001/jamanetworkopen.2021.34315.

Fraser, Nancy, and Linda Gordon. 1994. "“Dependency” Demystified: Inscriptions of Power in a Keyword of the Welfare State'. Social Politics 1 (1): 4-31. https://doi.org/10.1093/sp/1.1.4.

Gangl, Markus. 2010. 'Causal Inference in Sociological Research'. Annual Review of Sociology 36: 21-47. https://doi.org/10.1146/annurev.soc.012809.102702.

Gangl, Markus, and Andrea Ziefle. 2015. 'The Making of a Good Woman: Extended Parental Leave Entitlements and Mothers' Work Commitment in Germany'. American Journal of Sociology 121 (2): 511-63.

Gelfand, Michele J, Joshua Conrad Jackson, Xinyue Pan, Dana Nau, Dylan Pieper, Emmy Denison, Munqith Dagher, Paul A M Van Lange, Chi-Yue Chiu, and Mo Wang. 2021. 'The Relationship between Cultural Tightness-Looseness and COVID-19 Cases and Deaths: A Global Analysis.' Lancet Planetary Health 5196 (20): 1-10. https://doi.org/10.1016/S25425196(20)30301-6.

Golberstein, Ezra, Hefei Wen, and Benjamin F Miller. 2020. 'Coronavirus Disease 2019 (COVID-19) and Mental Health for Children and Adolescents'. JAMA Pediatrics 174 (9): 81920.

Goldstein, Dana, and Noam Scheiber. 2022. 'As More Teachers' Unions Push for Remote Schooling, Parents Worry. So Do Democrats.' The New York Times, 8 January 2022, sec. U.S. https://www.nytimes.com/2022/01/08/us/teachers-unions-covid-schools.html. 
Google LLC. 2020. 'Google COVID-19 Community Mobility Reports'. 2020.

https://www.google.com/covid19/mobility/.

Götzinger, Florian, Begoña Santiago-García, Antoni Noguera-Julián, Miguel Lanaspa, Laura

Lancella, Francesca I Calò Carducci, Natalia Gabrovska, et al. 2020. 'COVID-19 in Children and Adolescents in Europe: A Multinational, Multicentre Cohort Study'. The Lancet Child and Adolescent Health 4642 (20): 1-9. https://doi.org/10.1016/s2352-4642(20)30177-2.

Griglio, Elena. 2020. 'Parliamentary Oversight under the Covid-19 Emergency: Striving against Executive Dominance'. The Theory and Practice of Legislation 8 (1-2): 49-70. https://doi.org/10.1080/20508840.2020.1789935.

Grossmann, Matt, Sarah Reckhow, Katharine O. Strunk, and Meg Turner. 2021. 'All States Close but Red Districts Reopen: The Politics of In-Person Schooling During the COVID-19 Pandemic'. Educational Researcher 50 (9): 637-48. https://doi.org/10.3102/0013189X211048840.

Grunow, Daniela, Katia Begall, and Sandra Buchler. 2018. 'Gender Ideologies in Europe: A Multidimensional Framework'. Journal of Marriage and Family 80 (1): 42-60.

https://doi.org/10.1111/jomf.12453.

Gutierrez, Roberto G, Jean Marie Linhart, and Jeffrey S Pitblado. 2003. 'From the Help Desk: Local Polynomial Regression and Stata Plugins'. The Stata Journal 3 (4): 412-19.

Hale, Thomas, Samuel Webster, Anna Petherick, Toby Phillips, and Beatriz Kira. 2020. 'Oxford Covid-19 Government Response Tracker'. Blavatnik School of Government 25.

Hank, Karsten, and Anja Steinbach. 2021. 'The Virus Changed Everything, Didn't It? Couples' Division of Housework and Childcare before and during the Corona Crisis'. Journal of Family Research 33 (1): 99-114. https://doi.org/10.20377/jfr-488.

Hartney, Michael T, and Leslie K Finger. 2020. 'Politics, Markets, and Pandemics: Public Education's Response to COVID-19'.

Heavey, Laura, Geraldine Casey, Ciara Kelly, David Kelly, and Geraldine McDarby. 2020. 'No Evidence of Secondary Transmission of COVID-19 from Children Attending School in Ireland, 2020'. Eurosurveillance 25 (21): 2000903.

Heggeness, Misty L. 2020. 'Estimating the Immediate Impact of the COVID-19 Shock on Parental Attachment to the Labor Market and the Double Bind of Mothers'. Review of Economics of the Household 18 (4): 1053-78.

Hellevik, Ottar. 2009. 'Linear versus Logistic Regression When the Dependent Variable Is a Dichotomy'. Quality \& Quantity 43 (1): 59-74.

Hernán, Miguel A, and James M Robins. 2020. 'Causal Inference: What If'. Boca Raton: Chapman \& Hill/CRC 2020.

Hiekel, Nicole, and Mine Kühn. 2021. 'Mental Health before and during the COVID-19 Pandemic: The Role of Partnership and Parenthood Status in Growing Disparities between Types of Families.' WP-2021-013. 0 ed. Rostock: Max Planck Institute for Demographic Research. https://doi.org/10.4054/MPIDR-WP-2021-013. 
Hipp, Lena, and Mareike Bünning. 2020. 'Parenthood as a Driver of Increased Gender Inequality during COVID-19? Exploratory Evidence from Germany'. European Societies 23 (Sup1): S658673.

Hjálmsdóttir, Andrea, and Valgerður S. Bjarnadóttir. 2021. "I Have Turned into a Foreman Here at Home": Families and Work-Life Balance in Times of COVID-19 in a Gender Equality Paradise'. Gender, Work \& Organization 28 (1): 268-83. https://doi.org/10.1111/gwao.12552.

Hudde, Ansgar. 2018. 'Societal Agreement on Gender Role Attitudes and Childlessness in 38 Countries'. European Journal of Population 34 (5): 745-67. https://doi.org/10.1007/s10680-0179459-8.

Humphreys, Kathryn L., Myo Thwin Myint, and Charles H. Zeanah. 2020. 'Increased Risk for Family Violence during the COVID-19 Pandemic'. Pediatrics 164 (1): e20200982. https://doi.org/10.1542/peds.2020-0982.

ISSP Research Group. 2016. International Social Survey Programme: Family and Changing Gender Roles IV - ISSP 2012. GESIS Data Archive, Cologne. ZA5900 Data file Version 4.0.0. https://doi.org/10.4232/1.12661.

Jacobsen, John Kurt. 1995. 'Much Ado about Ideas: The Cognitive Factor in Economic Policy'. World Politics 47 (2): 283-310.

Jæger, Mads Meier, and Ea Hoppe Blaabæk. 2020. 'Inequality in Learning Opportunities during COVID-19: Evidence from Library Takeout'. Research in Social Stratification and Mobility 68 (August): 100524. https://doi.org/10.1016/j.rssm.2020.100524.

John, Peter. 1999. 'Ideas and Interests; Agendas and Implementation: An Evolutionary Explanation of Policy Change in British Local Government Finance'. The British Journal of Politics \& International Relations 1 (1): 39-62. https://doi.org/10.1111/1467-856X.00003.

- 2003. 'Is There Life After Policy Streams, Advocacy Coalitions, and Punctuations: Using Evolutionary Theory to Explain Policy Change?' Policy Studies Journal 31 (4): 481-98. https://doi.org/10.1111/1541-0072.00039.

Kampf, Günter, and Martin Kulldorff. 2021. 'Calling for Benefit-Risk Evaluations of COVID-19 Control Measures'. The Lancet 397 (10274): 576-77. https://doi.org/10.1016/S01406736(21)00193-8.

Kim, Soyoung, Yae-Jean Kim, Kyong Ran Peck, and Eunok Jung. 2020. 'School Opening Delay Effect on Transmission Dynamics of Coronavirus Disease 2019 in Korea: Based on Mathematical Modeling and Simulation Study'. Journal of Korean Medical Science 35 (13): e143.

Knight, Carly R., and Mary C. Brinton. 2017. 'One Egalitarianism or Several? Two Decades of Gender-Role Attitude Change in Europe'. American Journal of Sociology 122 (5): 1485-1532. https://doi.org/10.1086/689814.

Kostoff, Ronald N., Daniela Calina, Darja Kanduc, Michael B. Briggs, Panayiotis Vlachoyiannopoulos, Andrey A. Svistunov, and Aristidis Tsatsakis. 2021. 'Why Are We Vaccinating Children against COVID-19?' Toxicology Reports 8 (January): 1665-84. https://doi.org/10.1016/j.toxrep.2021.08.010. 
Kremer, Monique. 2007. How Welfare States Care: Culture, Gender and Parenting in Europe. Amsterdam University Press.

Kreyenfeld, Michaela, and Sabine Zinn. 2021. 'Coronavirus and Care: How the Coronavirus Crisis Affected Fathers' Involvement in Germany'. Demographic Research 44 (4): 99-124. https://doi.org/10.4054/DemRes.2021.44.4.

Kroska, Amy. 2007. 'Gender Ideology and Gender Role Ideology'. In The Blackwell Encyclopedia of Sociology. John Wiley \& Sons, Ltd. https://doi.org/10.1002/9781405165518.wbeosg019.

Landivar, Liana Christin, Leah Ruppanner, Lloyd Rouse, William J. Scarborough, and Caitlyn Collins. 2021. 'Research Note: School Reopenings During the COVID-19 Pandemic and Implications for Gender and Racial Equity'. Demography, November, 9613354. https://doi.org/10.1215/00703370-9613354.

Lau, Richard R, and David P Redlawsk. 2001. 'Advantages and Disadvantages of Cognitive Heuristics in Political Decision Making'. American Journal of Political Science 45 (4): 951-71.

Lee, Benjamin, and William V Raszka. 2020. 'COVID-19 Transmission and Children: The Child Is Not to Blame'. Pediatrics 146 (2): e2020004879.

Leopoldina. 2020. ‘Ad-Hoc-Stellungnahmen Zur Coronavirus-Pandemie'. Halle (Saale): Nationale Akademie der Wissenschaften Leopoldina. https://www.leopoldina.org/uploads/tx_leopublication/2020_LeopoldinaStellungnahmen_Coronavirus-Pandemie_1-7.pdf.

Li, Xue, Wei Xu, Marshall Dozier, Yazhou He, Amir Kirolos, and Evropi Theodoratou. 2020. 'The Role of Children in Transmission of SARS-CoV-2: A Rapid Review'. Journal of Global Health 10 (1): 011101.

Lippe, Tanja Van der, Judith De Ruijter, Esther De Ruijter, and Werner Raub. 2011. 'Persistent Inequalities in Time Use between Men and Women: A Detailed Look at the Influence of Economic Circumstances, Policies, and Culture'. European Sociological Review 27 (2): 164-79.

Luig, Judith. 2020. 'Schulöffnung: Endlich nicht mehr allein'. Die Zeit, 3 May 2020, sec. Gesellschaft. https://www.zeit.de/gesellschaft/schule/2020-04/schuloeffnung-grundschulecoronavirus-social-distancing-infektionsschutz-kinder.

Ma, Sen, Zhengyun Sun, and Hao Xue. 2020. 'Childcare Needs and Parents' Labor Supply: Evidence from the COVID-19 Lockdown'. Available at SSRN 3630842.

Macartney, Kristine, Helen E Quinn, Alexis J Pillsbury, Archana Koirala, Lucy Deng, Noni Winkler, Anthea L Katelaris, Matthew V N O'Sullivan, Craig Dalton, and Nicholas Wood. 2020. 'Transmission of SARS-CoV-2 in Australian Educational Settings: A Prospective Cohort Study'. The Lancet Child and Adolescent Health 4 (11): 807-16.

Marianno, Bradley D. 2021. 'Teachers' Unions: Scapegoats or Bad-Faith Actors in COVID-19 School Reopening Decisions?' Brookings (blog). 25 March 2021. https://www.brookings.edu/blog/brown-center-chalkboard/2021/03/25/teachers-unionsscapegoats-or-bad-faith-actors-in-covid-19-school-reopening-decisions/. 
Mason, Karen Oppenheim, and Larry L. Bumpass. 1975. 'U. S. Women's Sex-Role Ideology, 1970'. American Journal of Sociology 80 (5): 1212-19. https://doi.org/10.1086/225951.

Matthijs, Matthias. 2016. 'Powerful Rules Governing the Euro: The Perverse Logic of German Ideas'. Journal of European Public Policy 23 (3): 375-91.

McGowan, Michael. 2020. 'Packed Crowds and Euphoric Leaders: Australia Revels in CovidFree Days'. The Guardian, 15 November 2020.

Meraviglia, Cinzia, and Aurore Dudka. 2021. 'The Gendered Division of Unpaid Labor during the Covid-19 Crisis: Did Anything Change? Evidence from Italy'. International Journal of Sociology 51 (1): 64-75.

Mood, Carina. 2010. 'Logistic Regression: Why We Cannot Do What We Think We Can Do, and What We Can Do about It'. European Sociological Review 26 (1): 67-82.

OECD. 2018. 'Balancing Paid Work, Unpaid Work and Leisure'.

Orloff, Ann Shola. 2018. '10. Motherhood, Work, and Welfare in the United States, Britain, Canada, and Australia': In , edited by George Steinmetz, 321-54. Cornell University Press. https://doi.org/10.7591/9781501717789-013.

Oster, Emily. 2020. 'Schools Are Not Spreading Covid-19. This New Data Makes the Case.' The Washington Post, 20 November 2020.

Padamsee, Tasleem J. 2009. 'Culture in Connection: Re-Contextualizing Ideational Processes in the Analysis of Policy Development'. Social Politics: International Studies in Gender, State \& Society 16 (4): 413-45. https://doi.org/10.1093/sp/jxp018.

Pfau-Effinger, Birgit. 1998. 'Gender Cultures and the Gender Arrangement—a Theoretical Framework for Cross-national Gender Research'. Innovation: The European Journal of Social Science Research 11 (2): 147-66. https://doi.org/10.1080/13511610.1998.9968559.

Pfau-Effinger, Birgit. 2005a. 'Welfare State Policies and the Development of Care Arrangements'. European Societies 7 (2): 321-47.

. 2005b. 'Culture and Welfare State Policies: Reflections on a Complex Interrelation'. Journal of Social Policy 34 (1): 3-20. https://doi.org/10.1017/S0047279404008232.

Polyakova, Maria, Geoffrey Kocks, Victoria Udalova, and Amy Finkelstein. 2020. 'Initial Economic Damage from the COVID-19 Pandemic in the United States Is More Widespread across Ages and Geographies than Initial Mortality Impacts'. Proceedings of the National Academy of Sciences 117 (45): 27934 LP - 27939. https://doi.org/10.1073/pnas.2014279117.

Qian, Yue, and Sylvia Fuller. 2020. 'COVID-19 and the Gender Employment Gap among Parents of Young Children'. Canadian Public Policy 46 (S2): S89-101.

Rajan, Dheepa, Kira Koch, Katja Rohrer, Csongor Bajnoczki, Anna Socha, Maike Voss, Marjolaine Nicod, Valery Ridde, and Justin Koonin. 2020. 'Governance of the Covid-19 Response: A Call for More Inclusive and Transparent Decision-Making'. BMJ Global Health 5 (5): e002655. https://doi.org/10.1136/bmjgh-2020-002655. 
Reskin, Barbara F. 1988. 'Bringing the Men Back in: Sex Differentiation and the Devaluation of Women's Work'. Gender \& Society 2 (1): 58-81.

Ridgeway, Cecilia L, and Shelley J Correll. 2004. 'Unpacking the Gender System: A Theoretical Perspective on Gender Beliefs and Social Relations'. Gender \& Society 18 (4): 510-31.

Roser, Max, Hannah Ritchie, Esteban Ortiz-Ospina, and Joe Hasell. 2020. 'Coronavirus Pandemic (COVID-19)'. Published Online at OurWorldInData.Org. 2020. https://ourworldindata.org/coronavirus.

Rubin, Donald B. 1980. 'Randomization Analysis of Experimental Data: The Fisher Randomization Test Comment'. Journal of the American Statistical Association 75 (371): 59193.

Ruppanner, Leah, Caitlyn Collins, Liana Christin Landivar, and William J. Scarborough. 2021. 'How Do Gender Norms and Childcare Costs Affect Maternal Employment Across US States?' Gender \& Society 35 (6): 910-39. https://doi.org/10.1177/08912432211046988.

Ruppanner, Leah, Xiao Tan, William Scarborough, Liana Christin Landivar, and Caitlyn Collins. 2021. 'Shifting Inequalities? Parents' Sleep, Anxiety, and Calm during the COVID-19 Pandemic in Australia and the United States'. Men and Masculinities 24 (1): 181-88.

Russell, Beth S, Monica Hutchison, Rachel Tambling, Alexandria J Tomkunas, Horton, and Abagail L. 2020. 'Initial Challenges of Caregiving during COVID-19: Caregiver Burden, Mental Health, and the Parent-Child Relationship'. Child Psychiatry \& Human Development 51: 671-82.

Sabates, Ricardo, Emma Carter, and Jonathan M. B. Stern. 2021. 'Using Educational Transitions to Estimate Learning Loss Due to COVID-19 School Closures: The Case of Complementary Basic Education in Ghana'. International Journal of Educational Development 82 (April): 102377. https://doi.org/10.1016/j.ijedudev.2021.102377.

Scarborough, William J, Ray Sin, and Barbara Risman. 2019. 'Attitudes and the Stalled Gender Revolution: Egalitarianism, Traditionalism, and Ambivalence from 1977 through 2016'. Gender \& Society 33 (2): 173-200.

Schafer, Mark, and Stephen Walker. 2006. Beliefs and Leadership in World Politics: Methods and Applications of Operational Code Analysis. Springer.

Schmidt, Steffen C. E., Bastian Anedda, Alexander Burchartz, Ana Eichsteller, Simon Kolb, Carina Nigg, Claudia Niessner, Doris Oriwol, Annette Worth, and Alexander Woll. 2020.

'Physical Activity and Screen Time of Children and Adolescents before and during the COVID19 Lockdown in Germany: A Natural Experiment'. Scientific Reports 10 (1): 21780.

https://doi.org/10.1038/s41598-020-78438-4.

Sevilla, Almudena, and Sarah Smith. 2020. 'Sevilla / Smith (2020): Baby Steps: The Gender Division of Childcare during the COVID-19 Pandemic'. Oxford Review of Economic Policy 36 (Supplement_1): S169-86. https://doi.org/10.1093/oxrep/graa027.

Shafer, K., M. Milkie, and C. Scheibling. 2020. 'The Division of Domestic Labour before \& during the COVID-19 Pandemic in Canada'. https://doi.org/10.31235/osf.io/24j87.

Sinha, Ian P., Rachel Harwood, Malcolm G. Semple, Daniel B. Hawcutt, Rebecca Thursfield, 
Omendra Narayan, Simon E. Kenny, Russell Viner, Simon Langton Hewer, and Kevin W. Southern. 2020. 'COVID-19 Infection in Children'. The Lancet Respiratory Medicine 8 (5): 44647. https://doi.org/10.1016/S2213-2600(20)30152-1.

Sjöberg, Ola. 2004. 'The Role of Family Policy Institutions in Explaining Gender-Role Attitudes: A Comparative Multilevel Analysis of Thirteen Industrialized Countries'. Journal of European Social Policy 14 (2): 107-23. https://doi.org/10.1177/0958928704042003.

Snape, Matthew D., and Russell M. Viner. 2020. 'COVID-19 in Children and Young People'. Science 370 (6514): 286-88.

Songer, Donald R, and Stefanie A Lindquist. 1996. 'Not the Whole Story: The Impact of Justices' Values on Supreme Court Decision Making'. American Journal of Political Science 40 (4): 1049-63. https://doi.org/10.2307/2111742.

Spence, Janet T. 1993. 'Gender-Related Traits and Gender Ideology: Evidence for a Multifactorial Theory'. Journal of Personality and Social Psychology 64 (4): 624-35. https://doi.org/10.1037/0022-3514.64.4.624.

Stage, Helena B., Joseph Shingleton, Sanmitra Ghosh, Francesca Scarabel, Lorenzo Pellis, and Thomas Finnie. 2021. 'Shut and Re-Open: The Role of Schools in the Spread of COVID-19 in Europe'. Philosophical Transactions of the Royal Society B: Biological Sciences 376 (1829): 20200277. https://doi.org/10.1098/rstb.2020.0277.

Stein-Zamir, Chen, Nitza Abramson, Hanna Shoob, Erez Libal, Menachem Bitan, Tanya Cardash, Refael Cayam, and Ian Miskin. 2020. 'A Large COVID-19 Outbreak in a High School 10 Days after Schools’ Reopening, Israel, May 2020’. Eurosurveillance 25 (29): 2001352.

Stepanikova, Irena. 2012. 'Racial-Ethnic Biases, Time Pressure, and Medical Decisions'. Journal of Health and Social Behavior 53 (3): 329-43.

Sullivan, Oriel, Jonathan Gershuny, and John P Robinson. 2018. 'Stalled or Uneven Gender Revolution? A Long-term Processual Framework for Understanding Why Change Is Slow'. Journal of Family Theory \& Review 10 (1): 263-79.

Swinkels, Marij. 2020. 'How Ideas Matter in Public Policy: A Review of Concepts, Mechanisms, and Methods'. International Review of Public Policy 2 (3): 281-316.

https://doi.org/10.4000/irpp.1343.

The World Bank, UNESCO, and UNICEF. 2021. 'The State of the Global Education Crisis: A Path to Recovery'. Washington D.C., Paris, New York. https://www.unicef.org/media/111621/file/\%20The\%20State\%20of\%20the\%20Global\%20Educat ion\%20Crisis.pdf\%20.pdf.

Tillman, Erik R. 2013. 'Authoritarianism and Citizen Attitudes towards European Integration'. European Union Politics 14 (4): 566-89. https://doi.org/10.1177/1465116513483182.

Tjernström, Emilia, and Thomas Tietenberg. 2008. 'Do Differences in Attitudes Explain Differences in National Climate Change Policies?' Ecological Economics 65 (2): 315-24.

Treas, Judith, and Tsuio Tai. 2016. 'Gender Inequality in Housework across 20 European Nations: Lessons from Gender Stratification Theories'. Sex Roles 74 (11-12): 495-511. 
Tversky, Amos, and Daniel Kahneman. 1974. 'Judgment under Uncertainty: Heuristics and Biases'. Science 185 (4157): 1124-31.

UNESCO. 2021a. 'Global Tracking of COVID-19 Caused School Closures and Re-Openings Methodological Note'.

2021b. 'Mapping of Online Articles on Covid-19 and Gender'. 2021.

https://en.unesco.org/news/mapping-online-articles-covid-19-and-gender.

2022. 'Education: From Disruption to Recovery'. UNESCO. 25 January 2022.

https://en.unesco.org/covid19/educationresponse.

UNESCO Institute for Statistics. 2020. 'World Development Indicators'.

Viner, R., S. Russell, R. Saulle, H. Croker, C. Stansfield, J. Packer, D. Nicholls, et al. 2021.

'Associations of School Closures with and without Social Lockdown on Physical and Mental Health of Children and Young People during the First COVID-19 Wave: A Systematic Review'. JAMA Pediatrics. https://doi.org/10.1001/jamapediatrics.2021.3221.

Viner, Russell, Chris Bonell, Sarah-Jayne Blakemore, James Hargreaves, and Jasmina PanovskaGriffiths. 2022. 'Schools Should Still Be the Last to Close and First to Open If There Were Any Future Lockdown'. Bmj. British Medical Journal Publishing Group.

Viner, Russell, Simon Russell, Rosella Saulle, Helen Croker, Claire Stansfield, Jessica Packer, Dasha Nicholls, Anne-Lise Goddings, Chris Bonell, and Lee Hudson. 2022. 'School Closures During Social Lockdown and Mental Health, Health Behaviors, and Well-Being Among Children and Adolescents During the First COVID-19 Wave: A Systematic Review'. JAMA Pediatrics.

Vogt, Ragnar. 2020. 'Was das Leopoldina-Gutachten Merkel rät'. Der Tagesspiegel Online, 13 April 2020, sec. Wissen. https://www.tagesspiegel.de/wissen/schuloeffnungen-undmaskenpflicht-was-das-leopoldina-gutachten-merkel-raet/25736652.html.

Walsh, Sebastian, Avirup Chowdhury, Simon Russell, Vickie Braithwaite, Joseph Ward, Claire Waddington, Carol Brayne, Chris Bonell, Russell M Viner, and Oliver Mytton. 2021. 'Do School Closures Reduce Community Transmission of COVID-19? A Systematic Review of

Observational Studies'. MedRxiv.

Willeit, Peter, Robert Krause, Bernd Lamprecht, Andrea Berghold, Buck Hanson, Evelyn Stelzl, Heribert Stoiber, et al. 2021. 'Prevalence of RT-QPCR-Detected SARS-CoV-2 Infection at Schools: First Results from the Austrian School-SARS-CoV-2 Prospective Cohort Study'. The Lancet Regional Health - Europe 5 (June): 100086. https://doi.org/10.1016/j.lanepe.2021.100086.

Wu, Joseph T., Shujiang Mei, Sihui Luo, Kathy Leung, Di Liu, Qiuying Lv, Jian Liu, Yuan Li, Kiesha Prem, and Mark Jit. 2022. 'A Global Assessment of the Impact of School Closure in Reducing COVID-19 Spread'. Philosophical Transactions of the Royal Society A 380 (2214): 20210124.

Xue, Baowen, and Anne McMunn. 2021. 'Xue / McMunn (2021): Gender Differences in Unpaid Care Work and Psychological Distress in the UK Covid-19 Lockdown'. PLoS ONE 16 (3): e0247959. https://doi.org/10.1371/journal.pone.0247959.

Yamamura, Eiji, and Yoshiro Tsustsui. 2021. 'School Closures and Mental Health during the 
COVID-19 Pandemic in Japan'. Journal of Population Economics 34 (4): 1261-98.

https://doi.org/10.1007/s00148-021-00844-3.

Yee, Albert S. 1996. 'The Causal Effects of Ideas on Policies'. International Organization 50 (1): 69-108.

Yerkes, Mara A., Stéfanie C. H. André, Janna W. Besamusca, Peter M. Kruyen, Chantal L. H. S. Remery, Roos van der Zwan, Debby G. J. Beckers, and Sabine A. E. Geurts. 2020. "'Intelligent" Lockdown, Intelligent Effects? Results from a Survey on Gender (in)Equality in Paid Work, the Division of Childcare and Household Work, and Quality of Life among Parents in the Netherlands during the Covid-19 Lockdown'. PLOS ONE 15 (11): e0242249. https://doi.org/10.1371/journal.pone.0242249.

Yildirim, T Murat, and Hande Eslen-Ziya. 2021. 'The Differential Impact of COVID-19 on the Work Conditions of Women and Men Academics during the Lockdown'. Gender, Work \& Organization 28 (S1): 243-49.

Zamarro, Gema, and María J. Prados. 2021. 'Gender Differences in Couples' Division of Childcare, Work and Mental Health during COVID-19'. Review of Economics of the Household 19 (1): 11-40. https://doi.org/10.1007/s11150-020-09534-7.

Zimmermann, Petra, Laure F. Pittet, and Nigel Curtis. 2021. 'How Common Is Long COVID in Children and Adolescents?' The Pediatric Infectious Disease Journal 40 (12): e482. 